\title{
Assessment of the Design Spectrum with Aggravation Factors by 2D Nonlinear Numerical Analyses: A Case Study in Gemlik Basin, Turkey
}

BíLAL ÖZASLAN ( $\sim$ ozaslanb@itu.edu.tr)

Istanbul Technical University https://orcid.org/0000-0001-7951-1759

Recep lyisan

Istanbul Technical University: Istanbul Teknik Universitesi

Emre Murat Hasal

Bursa Metropolitan Municipality: Bursa Buyuksehir Belediyesi

Hadi Khanbabazadeh

Gebze Technical University: Gebze Teknik Universitesi

Hiroaki Yamanaka

Tokyo Institute of Technology School of Environment and Society: Tokyo Kogyo Daigaku Kankyo Shakai Rikogakuin

\section{Research Article}

Keywords: Aggravation factor, Nonlinear analysis, Basin effect, 2D Site response, Gemlik basin, Finite Difference Method

Posted Date: April 16th, 2021

DOl: https://doi.org/10.21203/rs.3.rs-415483/v1

License: (9) (1) This work is licensed under a Creative Commons Attribution 4.0 International License. Read Full License

Version of Record: A version of this preprint was published at Bulletin of Earthquake Engineering on January 14th, 2022. See the published version at https://doi.org/10.1007/s10518-021-01296-6. 


\title{
Assessment of the Design Spectrum with Aggravation Factors by 2D Nonlinear Numerical Analyses: A Case Study in Gemlik Basin, Turkey
}

\author{
B. OZASLAN ${ }^{\mathrm{a}, 1}$, R. IYISAN ${ }^{\mathrm{b}}$, M. E. HASAL ${ }^{\mathrm{c}}$, H. KHANBABAZADEH ${ }^{\mathrm{d}}$ and H. YAMANAKA ${ }^{\mathrm{e}}$ \\ ${ }^{a, b}$ Istanbul Technical University, Faculty of Civil Engineering, 34469 Maslak, Istanbul, Turkey \\ ${ }^{c}$ Bursa Metropolitan Municipality, Civil Engineering Department, 16080 Osmangazi, Bursa, Turkey \\ ${ }^{d}$ Gebze Technical University, Department of Construction, 41400 Gebze, Kocaeli, Turkey \\ ${ }^{e}$ Tokyo Institute of Technology, Department of Environment Science and Technology, 4259 Nagatsuta, Yokohama, \\ Kanagawa, 226-8503, Japan
}

\begin{abstract}
The response spectra of multidimensional analyses are compared with the one-dimensional (1D) local models to couple the irregular soil stratification effect in a site. In recent studies, the surface motion spectra ratios of 2D/1D or $3 \mathrm{D} / 1 \mathrm{D}$ are defined as spectral aggravation factors for each region in a site. Particularly in alluvial basins, where the soil media is typically formed by fault ruptures or topographic depressions filled with sediments, the inclination of the rock outcrop in the edge of the basin has a considerable effect on the site response, and such effect has not yet been taken into consideration of recent seismic building codes and general engineering applications. In this study, the natural alluvial basin near the North Anatolian Fault in Gemlik, Maramara Region, Turkey, was investigated by 40 seismic site tests and 4 validation borings. The $2 \mathrm{D}$ and $1 \mathrm{D}$ nonlinear response history analyses in north-south and eastwest directions of the Gemlik basin were performed by numerical model on finite difference scheme considering nonlinear elasto-plastic material behaviors and geometric discontinuities. 22 strong ground motions recorded on rock site are excited vertically as SH waves. The numerical results exhibited the narrow basin effects are derived not only by reflection, refraction, and shifting behavior but also by focusing and superposition of the seismic waves propagating from both opposite basin edges. As a result, the site-specific spectral aggravation factors, $\mathrm{SAF}_{2 \mathrm{D} / 1 \mathrm{D}}$ defined by the ratio between the 2D and 1D acceleration response spectra for each period and any location on the site, were proposed for the Gemlik basin. The variations of the aggravation factors were observed as increasing values to 1.2-2.2 on the near edge and basin center.
\end{abstract}

Keywords: Aggravation factor; Nonlinear analysis; Basin effect; 2D Site response; Gemlik basin; Finite Difference Method

\footnotetext{
${ }^{1}$ Corresponding author.

Bilal Ozaslan

E-mail: ozaslanb@itu.edu.tr

aORCID: 0000-0001-7951-1759, ' ORCID: 0000-0002-0887-9983, 'ORCID: 0000-0003-3466-7885,

dORCID: 0000-0001-9764-7799, '्eRCID: 0000-0002-5937-4707
} 


\section{Introduction}

The design of earthquake-resistant structures in living quarters is one of the significant objectives of civil engineering. The prediction of the hazards on all living facilities to protect lives by reducing the destructive effect of earthquakes has always been crucial in terms of engineering. To estimate a design earthquake is the main phenomenon in the design of a building and has a crucial role in examining the existing building performance to minimize the loss of life and property. In the site response investigations performed last decades, the acquirements have pointed to four main aspects that shape the strong ground motions. The first is the amplification of displacement which exists when a seismic wave progresses through an interface to lower rigidity layers from the higher rigidity ones. The second is the resonance of the flat layers developed mechanically at specific frequencies. The third originates from the nonlinearity of soil stress-strain behavior and the nature of inhomogeneity and anisotropy in the material. The last effect derives from the wave propagation variation in the soil half-space, which has multilayered site conditions with stratigraphic heterogeneities.

In early studies, to reveal the effect of plane-incident wave in soft two-dimensional basin Aki and Larner (1970), Wong and Trifunac (1974) estimated surface motion of valleys with perfectly elastic material for incident plane SH rays by semi-analytical method. Smith (1975) performed analyses using finite difference and finite element techniques to study the effects of irregular layer interface systematically. Bard and Bouchon (1980a) examined the formation of surface waves and edge effects. King and Tucker (1984) noted significant differences in surface peak horizontal accelerations at the center and near the edges of the valleys. Yamanaka (1989) performed in situ investigation and numerical analysis to study the propagation of the seismic waves within the deep sedimentary layers of southwestern Kanto district, Japan. Papageorgiou and Kim (1991) investigated the effect of bedrock slope on amplifications by establishing a 2D model in the Caracas basin in Venezuela during the Caracas earthquake on 29 July 1967. Zhang and Papageorgiou (1996) worked at the Marina basin in San Francisco, California, to predict the impact of the Loma Prieta earthquake on 18 October 1989. Pei and Papageorgiou (1996) studied the surface waves created by motions traveling up from the basin bottom on the records from Gilroy seismograph arrays placed on the surface along the Santa Clara basin in California. Kawase (1996) used the 2D Finite Element model to analyze the basin edge effect along the damaged zone in the Kobe basin observed in the Hyogoken Nanbu earthquake on 17 January 1995. Graves et al. (1998) suggested that amplification increase was directly caused by surface waves generated from the basin edge. Bielak et al. (1999) evaluated soil amplification and structural damage together in a small valley in Kirovakan depending on basin conditions. The performed 1D wave propagation analyses could not provide sufficient results for the existence and spatial distribution of the 1988 Armenia (Spitak) earthquake damage over a wide area in Kirovakan. In the progressive stages of the multidimensional response studies, the concept of aggravation factor was proposed by Chávez-García and Faccioli (2000) Bakir et al. (2002) analyzed the strong ground motion in the Dinar district, where the 2D model was established on the edge of an alluvial basin in Southeastern Anatolia during the Dinar earthquake. Somerville et al. (2003) asserted that commonly used empirical approaches do not reflect the additional effects of sedimentary basins. In relevant studies, Semblat et al. (2005), Bard et al. (2010), Iyisan and Hasal (2011), Iyisan and Khanbabazadeh (2013), Abraham et al. (2016), Khanbabazadeh et al. (2016), Riga et al. (2016), Makra and ChávezGarcía (2016), Chávez-García FJ et al. (2018), Cipta et al. (2018), Moczo et al. (2018), Zhu et al. (2018), the results 
found in the two-dimensional numerical analyses support this situation. In the current researches, Hasal et al. (2018), Khanbabazadeh et al. (2018; 2019), Ozaslan et al. (2020), it has been studied by time-domain dynamic analyses in idealized 2D models of Dinar and Düzce basins.

This study presents the effects of the heterogeneities in both vertical and lateral directions to the local seismic response by concentrating on the earthquake response analysis of the basin which is laterally confined and in the form of filledsediment. In this aspect, a nonlinear soil behavior was examined under the risk-targeted levels consisted of design and maximum considered earthquakes. For this purpose, the proposed procedure is based on the correlation between detailed numerical modeling solutions to extract the contributions due to 2D effects additional to $1 \mathrm{D}$ soil behavior. The impacts of a multiaxial stress state in the soil, formed by a 2D-3D decomposed shallow stratigraphy, need to be investigated since they can play a remarkable role in the resulting nonlinear strains. In this study, comprehensive insitu investigation and numerical analyses were performed to study the site response and propagation of the seismic waves within the shallow sedimentary basin in the Gemlik district of western Marmara Sea, Turkey. In the scope of the study, the effects of lateral discontinuities defined as basin geometry and slope of the bedrock on accelerations of design earthquake were investigated by nonlinear numerical analyses on natural basin conditions.

\section{Site Investigations}

\subsection{Seismic array tests and borings}

Gemlik basin in Bursa, located between latitudes of $40^{\circ} 2624 \mathrm{~N}-40^{\circ} 2516 \mathrm{~N}$ and the longitudes of $29^{\circ} 90 \mathrm{E}-29^{\circ} 1120 \mathrm{E}$, has been determined as the research area. The basin, which is around $1.7 \mathrm{~km}$ width in the north-south direction and $2.5 \mathrm{~km}$ long in the east-west direction, is enclosed by two fault segments on the southwestern branch of the North Anatolian Fault. The alluvium deposit and bedrock form in the basin have been assessed by a large number of microtremor array measurements and validation borings. Microtremor array measurements have been made at 40 different research points in total with two instrument sets. The recorded microtremors have been analyzed by performing the SPAC method using Fortran codes to create a detailed underground model of the basin (Okada and Suto 2003; Yamanaka 2005). Besides, confirmatory drillings and Standard Penetration Tests have been performed in 4 sites. The coordinates of the all site investigations are presented with emphasis on the methodologies and tools employed in Figure 1 and Figure 2, respectively. In the seismic experiments, a circular array consisting of seven equally spaced stations around the central station has been preferred because of its feasibility in the highly intensive residential areas. In this method, the phase velocities of Rayleigh waves are computed on cross-correlations between each station pairs on the circular array by analyzing vertical components of microtremors. The array consists of three stations located on the corners of two equilateral triangles and a three-components station at the center of the circle. The observed phase velocities are employed to the estimation of the shear wave velocities and layer thicknesses by performing inversion with Genetic Algorithm and Simulated Annealing method, which generates optimization in mutations, crossover, and selection of individuals in a population (Yamanaka and Ishida 1996) 


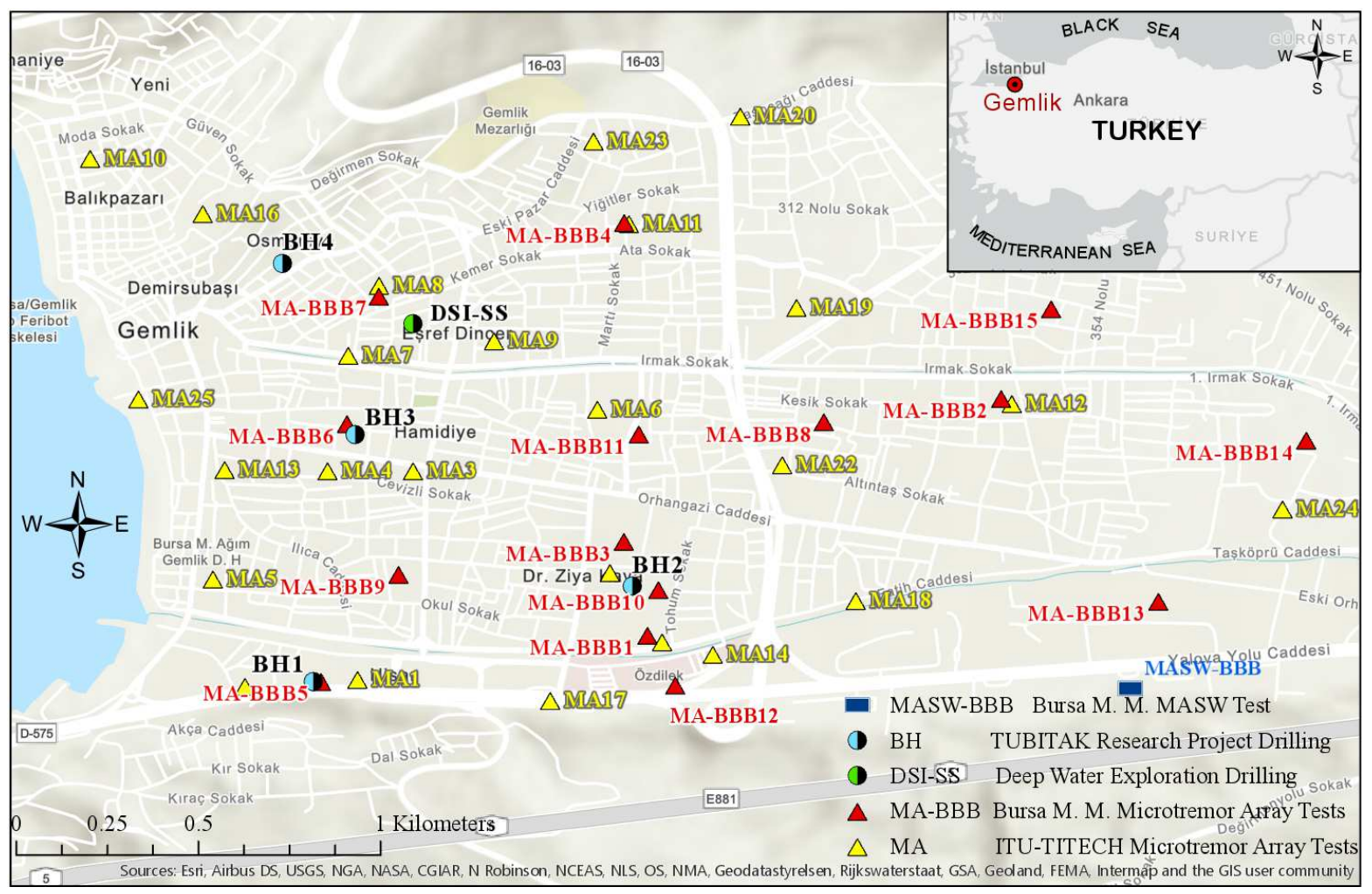

Figure 1. Site investigations in Gemlik district, Turkey

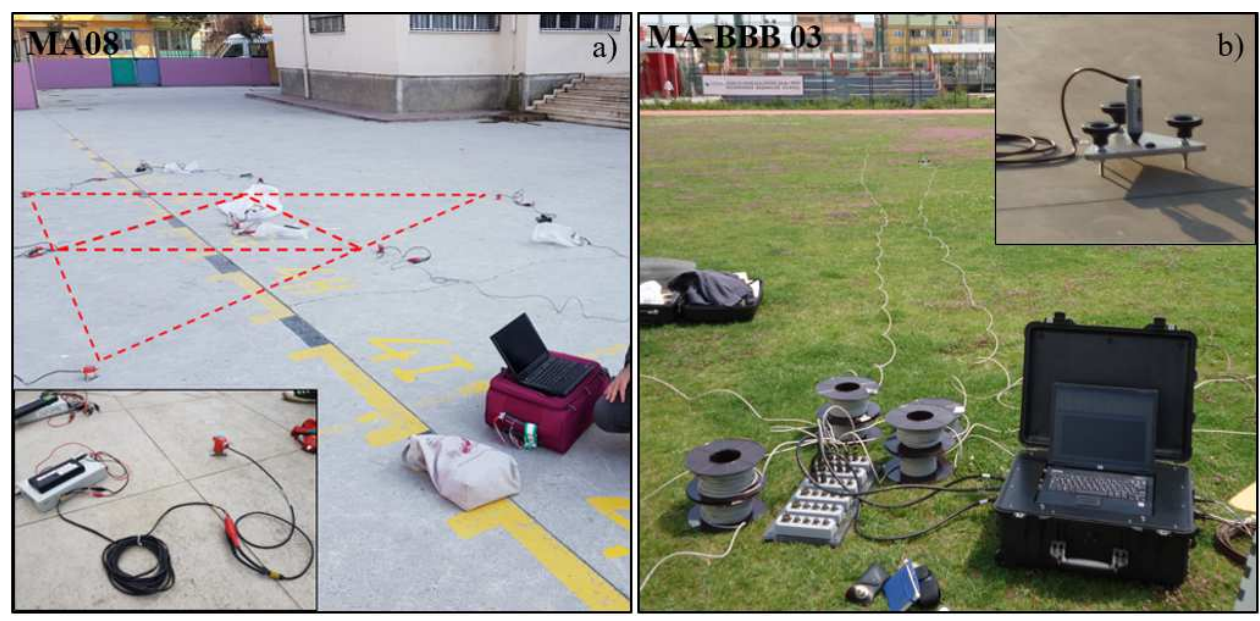

Figure 2. Array plan and two different microtremor sets a) ITU-TITECH MA measurements, b) Bursa Metropolitan Municipality MA-BBB measurements

The applied sizes of the array circle have ranged from $20 \mathrm{~m}$ to $50 \mathrm{~m}$ in radius. The phase velocities of Rayleigh waves have been estimated by 20-30 minutes long microtremor data, and the shear wave velocities of the soil layers have been determined by the inversion method. It has been revealed that the soil structure consists of two layers lied on the bedrock whose mean S-wave velocities are around $180 \mathrm{~m} / \mathrm{s}$ and $500 \mathrm{~m} / \mathrm{s}$ in Figure 3. Microtremor measurements have been completed by using the test set of Tokyo Institute of Technology with the frequency range from 3 to $100 \mathrm{~Hz}$ and 
the test set Bursa Metropolitan Municipality with Guralp CMG-DM24S24 Laptop integrated 24 channel portable seismic recorder system with $1-500 \mathrm{~Hz}$ vertical feedback geophones.

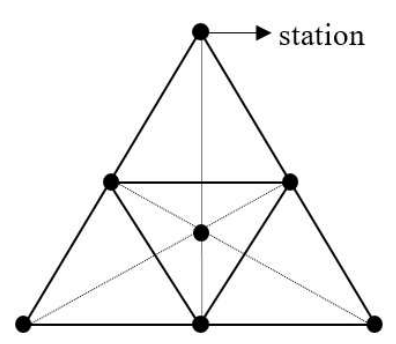

Microtremor array method

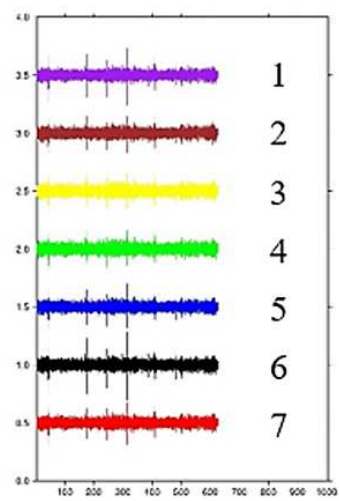

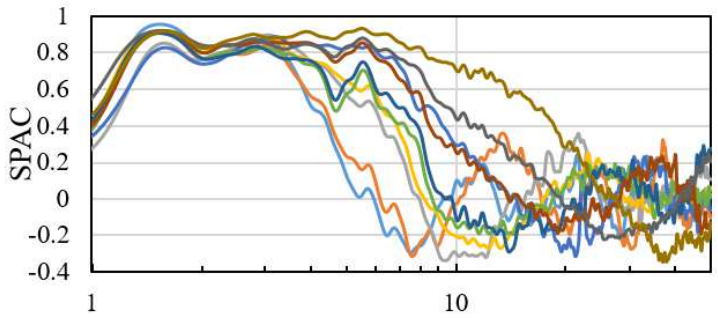

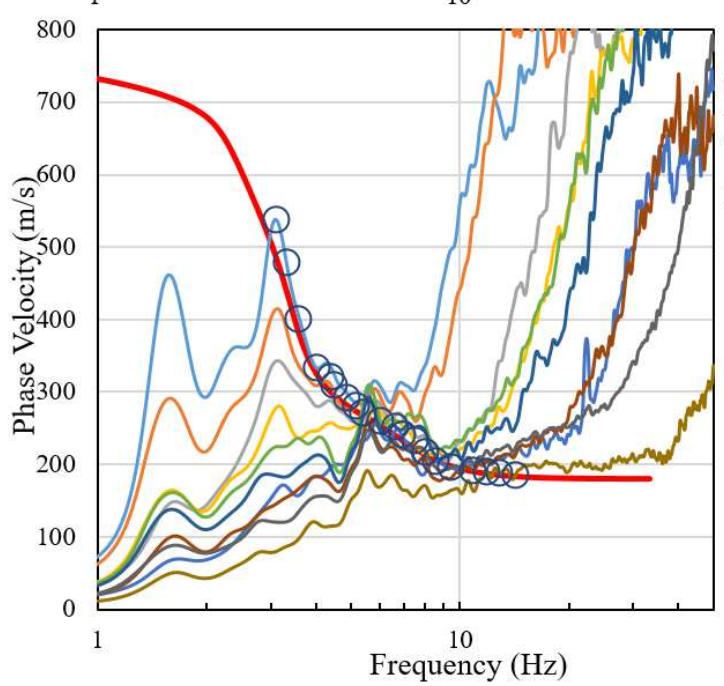

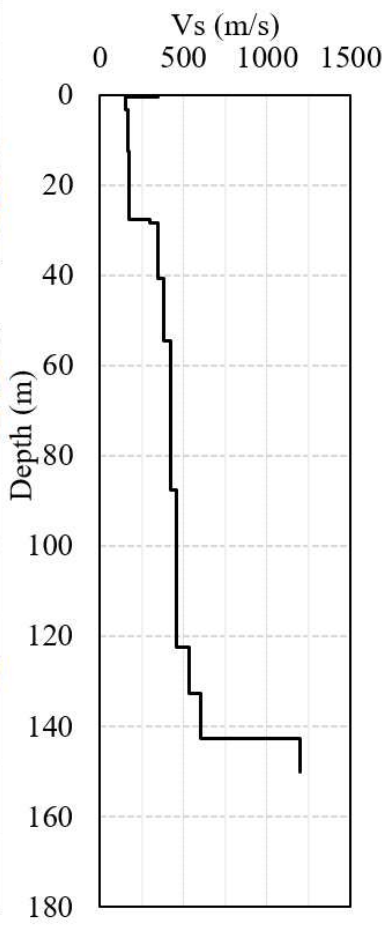

Figure 3. Array measurement plan, data set, phase velocity and SPAC coefficients and Vs profile

The accuracy of the soil section models created in the study was controlled by the consistency of the data collected in both seismic and penetration tests. For this purpose, $\mathrm{BH} 1, \mathrm{BH} 2, \mathrm{BH} 3$, and $\mathrm{BH} 4$ investigation borings and penetration tests were performed at the same points with the microtremor measurements, MA BBB-5, MA BBB-6, MA BBB-7, and MA BBB-10, which were made in the basin center and near the edges.

In the borings, $\mathrm{BH} 1$ and $\mathrm{BH} 2$ medium to high plasticity clay and silty clay unit are observed to the depth of $8 \mathrm{~m}-12 \mathrm{~m}$. The Triassic Abadiye formation belongs to the Karakaya group, which consists of meta claystone, metasiltstone, metasandstone, and metalimestone. The unit in question is generally very weathered, very weak, and fragmented because it is in the fault zone. It is fully weathered residual soils (sandy, silty clay), and the weathering degree decreases towards the end of the boring. In the third and fourth boreholes, a silty clay unit with a fine sand band, grayish color, and medium to high plasticity have been passed between $2 \mathrm{~m}-30 \mathrm{~m}$. These units are Quaternary-aged alluvium. Under the alluvial layers, there is a residual soil (sandy, gravelly clay) deeper than $35 \mathrm{~m}$ until the end of the borings, and it is predicted to have formed after the complete weathering of the Triassic Abadiye formation belonging to the Karakaya group. In the 4th borehole, shells belonging to sea creatures are observed in the boring sample after $20 \mathrm{~m}$ in the formation (Okay and Güncüoğlu 2004). The alluvial deposits in the main lithological units detected in boring logs BH1-BH4 in the Gemlik basin are given in Figure 4. 


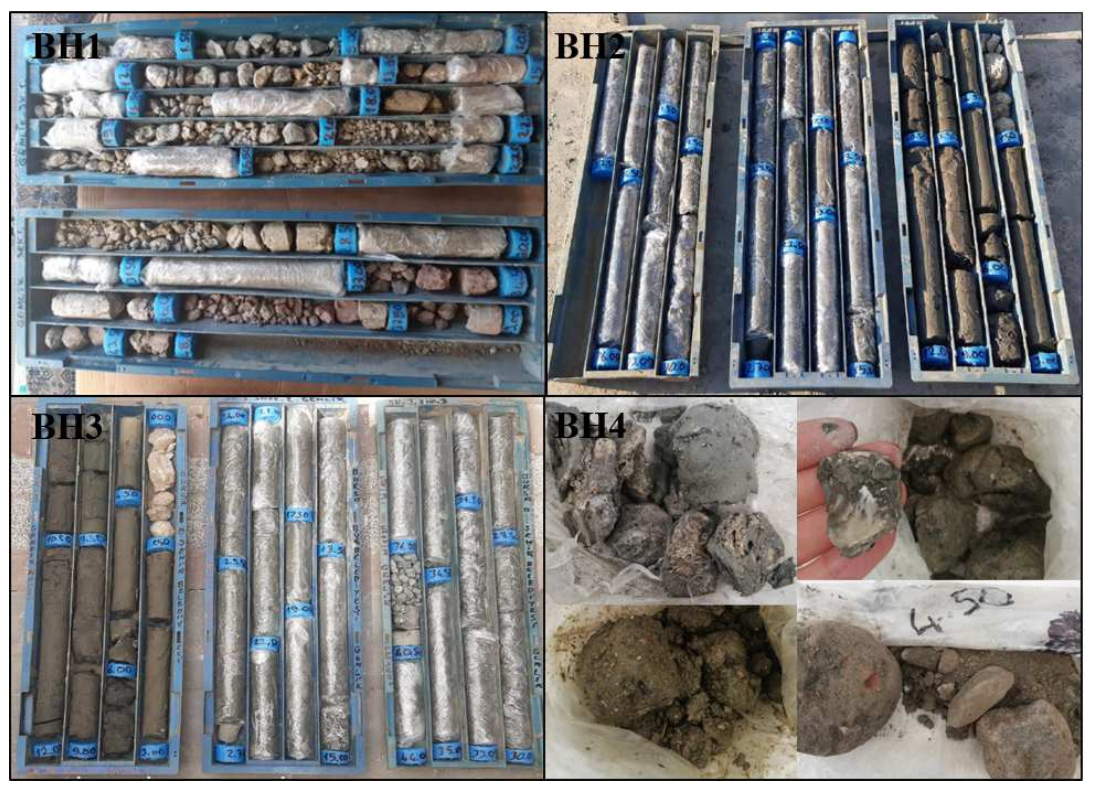

Figure 4. The alluvial deposits in the main lithology discovered by borings BH1-BH4 in Gemlik basin

The correlations suggested by Imai (1977), JRA (1980), Iyisan (1996) were used to calculate the variation of shear wave velocity of the Standard Penetration Test data. The mean of the three different equations $\mathrm{V}_{\mathrm{s}}=102 \mathrm{~N}^{0.292}$, $\mathrm{V}_{\mathrm{s}}=100 \mathrm{~N}^{0.33}, \mathrm{~V}_{\mathrm{s}}=51.5 \mathrm{~N}^{0.516}$ (respectively, where $\mathrm{N}$ is the number of blows) was compared with the results of the seismic tests in Figure 5. In the borings, $\mathrm{BH} 3$ and $\mathrm{BH} 4$, which are closer to the basin center, the Standard Penetration Test blow counts (SPT- N) take lower values ranging from 5 to 15 in the upper layer with 10-40 m depth while these values increase to 20 to 40 after $35 \mathrm{~m}$ depth. In the borings located on the near edges of the basin, the mentioned increase starts from 10-20 m depth.
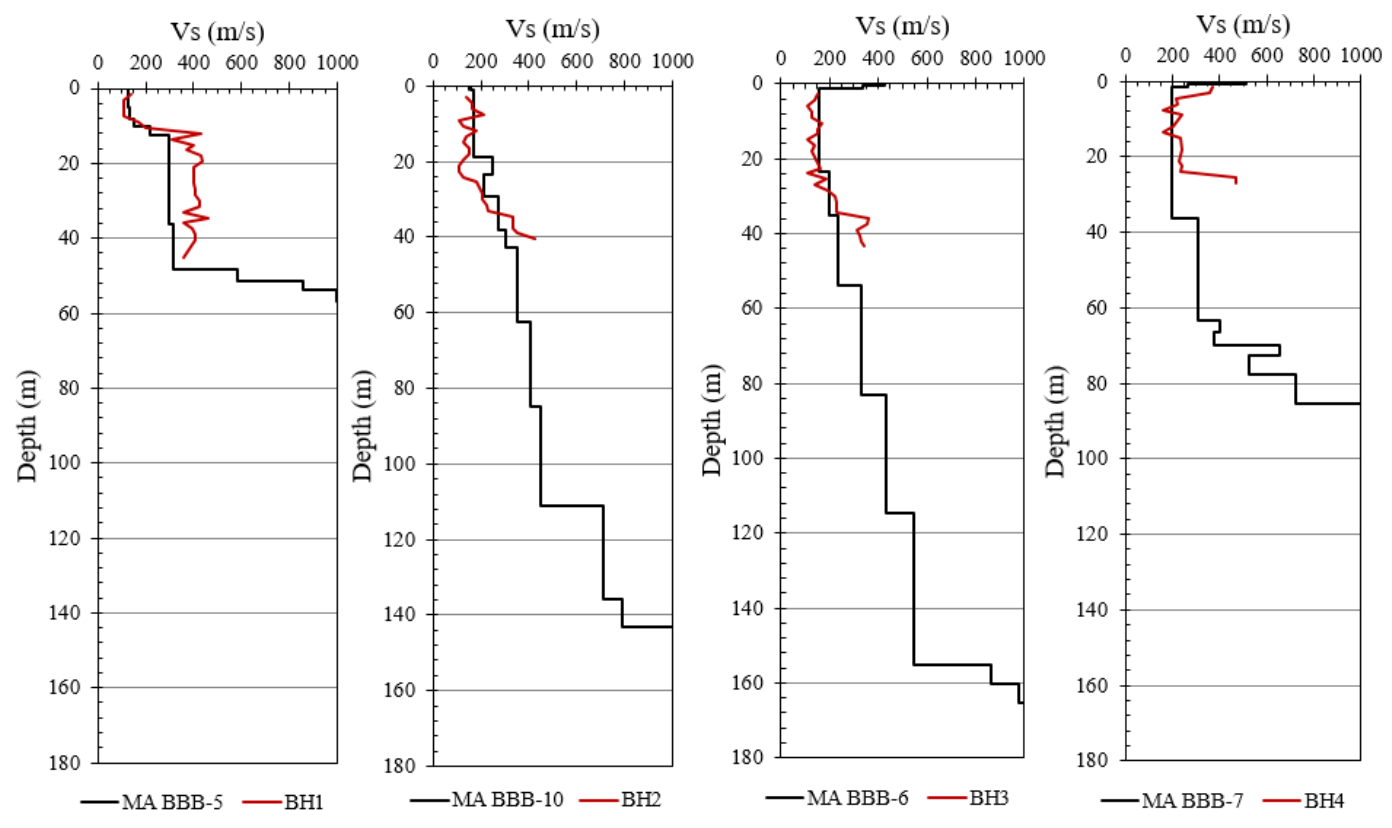

Figure 5. Comparison of the shear wave profiles of seismic test and SPT 


\subsection{The soil condition and basin geometry}

Geographical Information System (GIS) was used to integrate all collected data on storing, evaluating, and presenting the field investigations. It provided the visualization of the layers created with the interpolation analysis of the spatial locations of the whole field study in 2D and 3D maps and helped the preparation of sections by establishing relations between data. The variation of bedrock depth along the basin base detected in simultaneous microtremor array measurements is presented in Figure 6. In addition, the resultant 2D layered basin models in the north-south direction (section A-A) and east-west direction (section B-B) are given by shear wave velocity intervals in Figure 7.

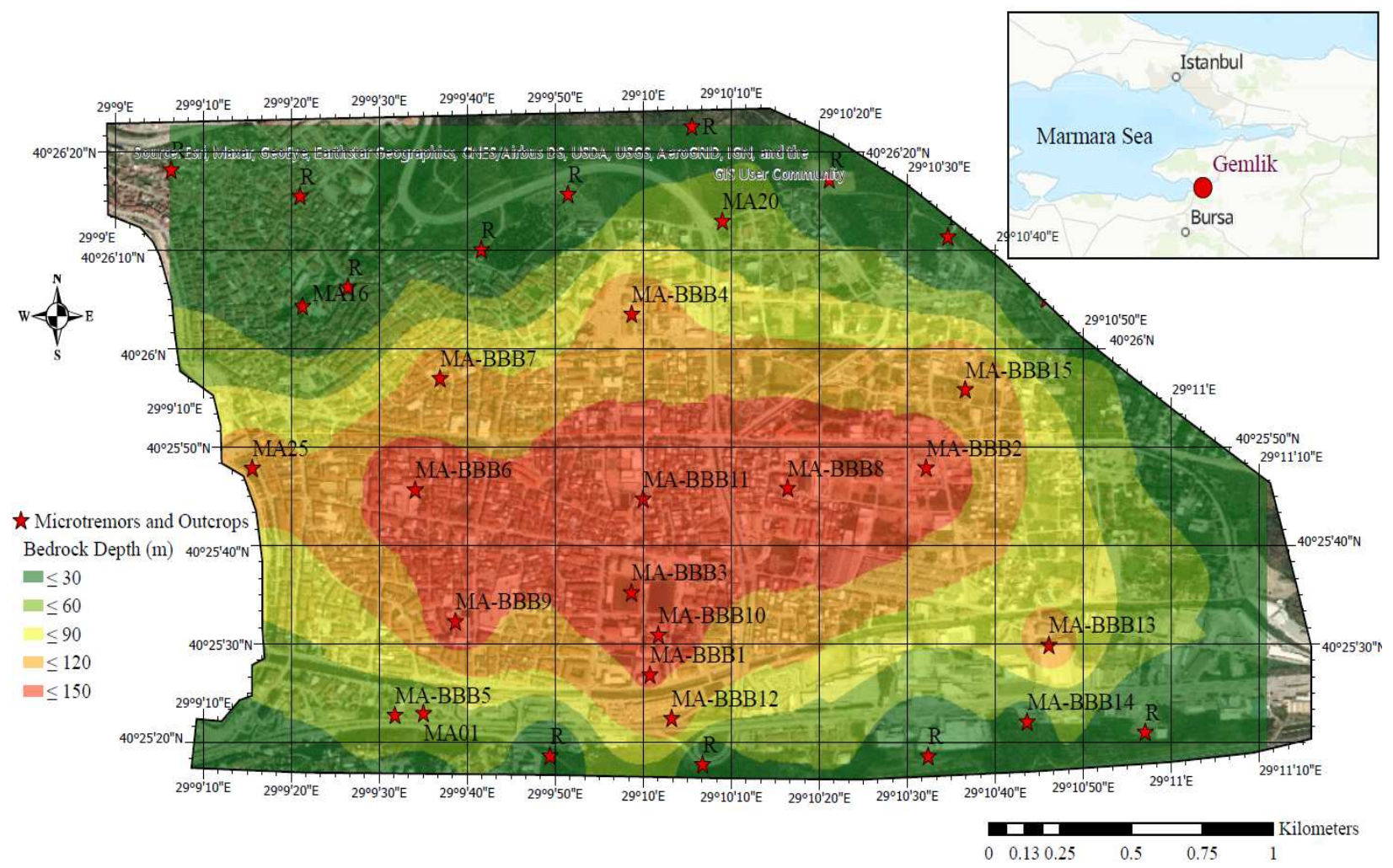

Figure 6. Bedrock depth by shear wave velocities in Gemlik basin

The Gemlik basin is a relatively shallow sedimentary structure with gentle slopes in the East-West direction, while the North-South direction has high inclined rock outcrops on the edges. The basin has a complicated geometry, where the depth of the soil deposit is estimated as $140 \mathrm{~m}-180 \mathrm{~m}$ at the center, overlie a rigid bedrock, and surrounded by an inclined rock outcrop. The 2D models of shear wave velocity exhibited the bedrock inclinations of the basin edges which extend with $\alpha_{1}=18^{\circ}, \alpha_{2}=10^{\circ}$ in North direction and $\alpha_{3}=16^{\circ}, \alpha_{4}=32^{\circ}$ in South direction and the $400 \mathrm{~m}$ length flat interface between the bedrock and the soil deposit. On the East-West direction, there is the broader flat base with $1400 \mathrm{~m}$ and the edge slopes with $\alpha_{5}=9^{\circ}, \alpha_{6}=10^{\circ}$ in Figure 7. 


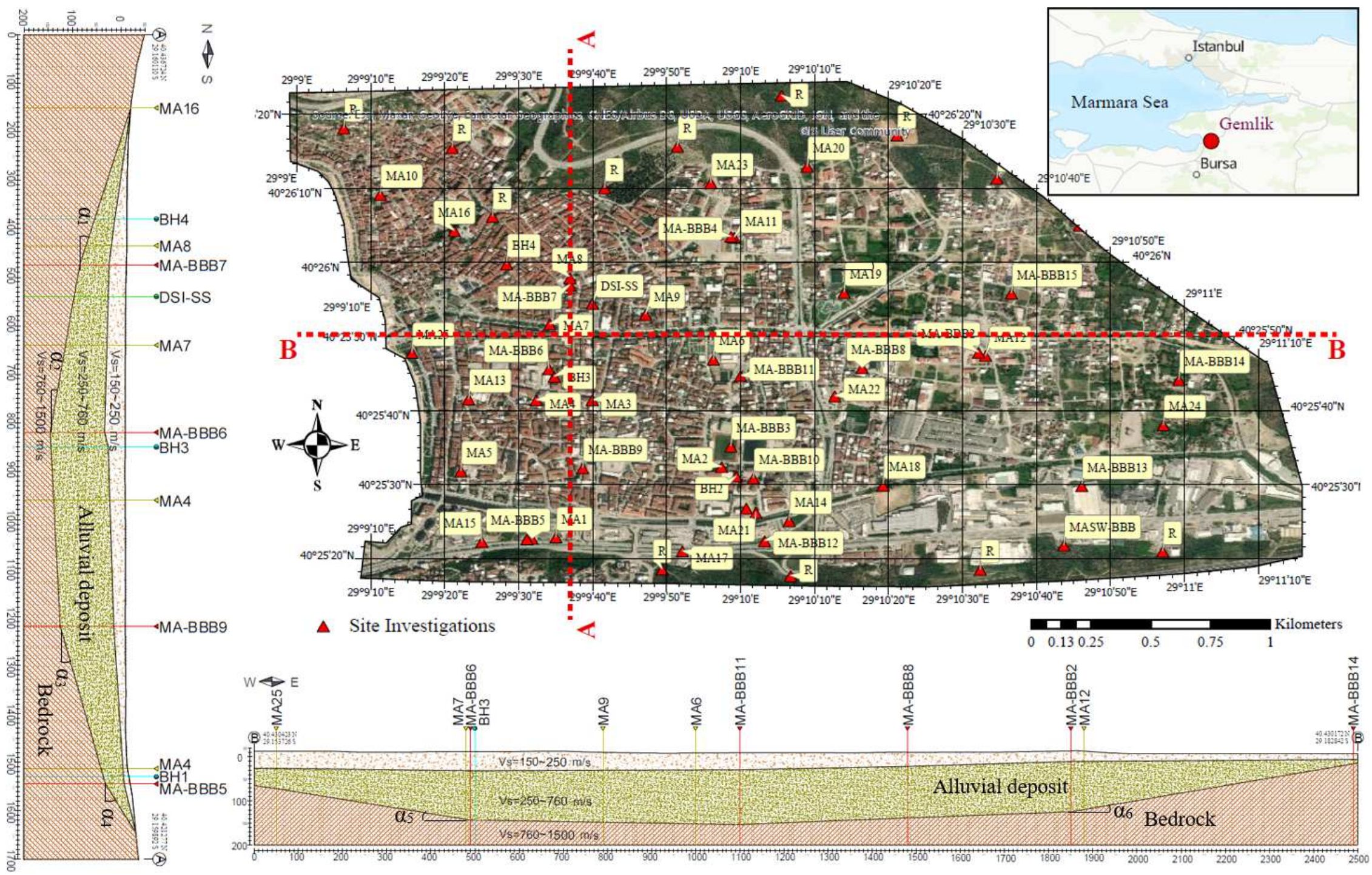

Figure 7. The variation of the bedrock and layers inclinations in A-A and B-B sections and the positions of the site investigations 


\section{Site Response Analyses by Numerical Models}

\subsection{Description of Finite Difference-based nonlinear method}

In the nonlinear 1D and 2D response history analyses of the basin, the explicit finite difference method has been performed by FLAC3D code (Fast Lagrangian Analysis of Continua 3D). Contrary to previous studies, this method provides elastoplastic soil nonlinearity under shear and compressional wave propagation by considering straindependent nonlinear constitutive rule and yielding criteria at any time during dynamic excitation in the same simulation. In this way, the averaged strain rate calculations over all subzones on the soil space mesh are performed before any calls of computation step by regarding constitutive model functions of the soil materials without any other damping requirement.

In the numerical analysis, the soil constitutive model needs to reflect nonlinear elastoplastic material properties under cyclic load in the time domain. In the applied constitutive model, energy dissipation is provided by the hysteretic model with the degradation of shear modulus $\left(\mathrm{G} / \mathrm{G}_{\max }\right)$ and cyclic damping (D) at small strain levels. Furthermore, the plastic deformations of soil materials at high strain levels are by the Mohr-Coulomb model. The combination of straindependent damping ratio and secant modulus functions are derived by given equations and illustrated by Figure 8 (a). A loop tracked on an initial cycle of unloading/reloading is illustrated in Figure 8 (b).

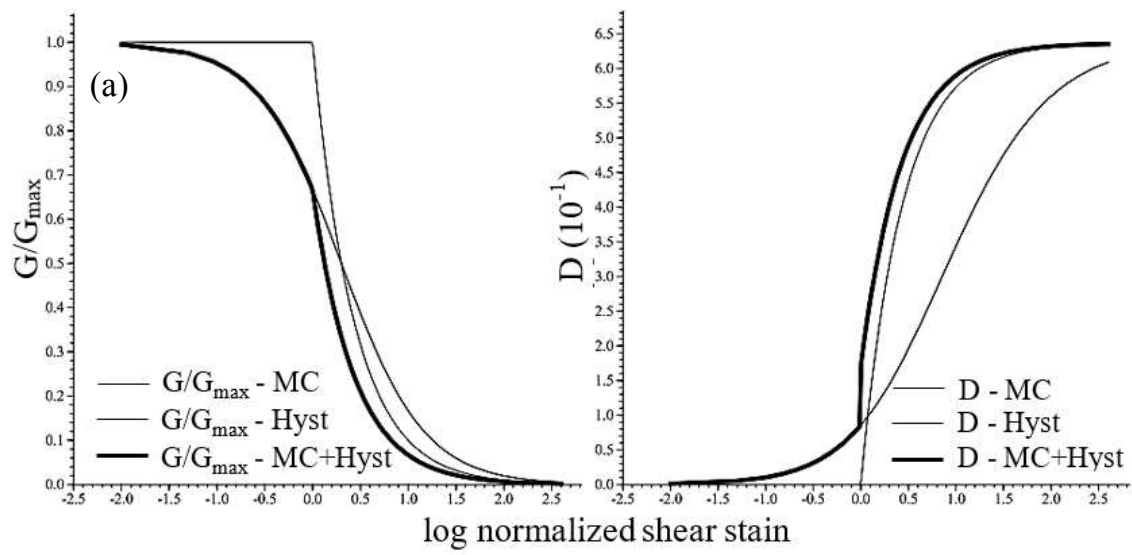

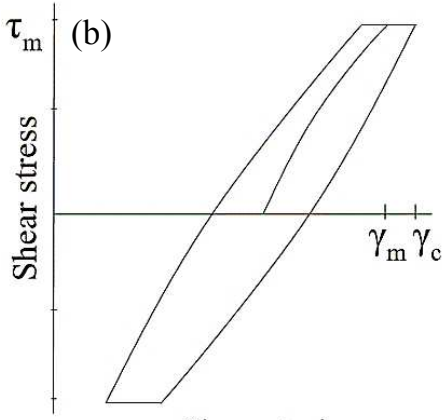

Shear strain

Figure 8. (a) Shear modulus and damping with shear strain of three different cases, (b) Shear stress-strain loop, Mohr-Coulomb model with hysteretic damping (Itasca, 2017)

Subsequently, the yielding level of the hyperbolic rule must be higher than the Mohr-Coulomb yield stress. The state is provided with the condition given in the equation below (Cundall 2001).

$$
\gamma_{\text {ref }}>\gamma_{\mathrm{m}}
$$

Where $\gamma_{\text {ref }}$ is the ultimate value of $\tau_{\mathrm{m}} / \mathrm{G}_{\mathrm{maks}}$ in hysteretic function, $\mathrm{G}_{\max }$ is maximum shear modulus, $\tau_{\mathrm{m}}, \gamma_{\mathrm{m}}$ are constant yield stress and shear strain, respectively.

$$
\gamma_{m}=\frac{\tau_{m}}{G_{\max }}
$$


In the elastic range, $\gamma_{\mathrm{c}}<\gamma_{\mathrm{m}}$, the modulus reduction factor is defined by Equation 3,

$$
G / G_{\max }=\frac{1}{1+\frac{|\gamma|}{\gamma_{\text {ref }}}}
$$

In the plastic range, $\gamma_{\mathrm{c}} \geq \gamma_{\mathrm{m}}$

$$
G / G_{\max }=\frac{1}{1+\frac{\gamma_{m}}{\gamma_{\text {ref }}}|\gamma|}
$$

The energy dissipation in a cycle, $\Delta \mathrm{W}$, is expressed as the total of contributions from elastic $\Delta \mathrm{W}_{\mathrm{H}}$, and plastic $\Delta \mathrm{W} \mathrm{MC}$ ranges.

$$
\begin{aligned}
& \Delta \mathrm{W}=\Delta \mathrm{W}_{\mathrm{H}}+\Delta \mathrm{W}_{\mathrm{MC}} \\
& \Delta \mathrm{W}_{\mathrm{H}}=4 G_{\text {maks }} \gamma_{\text {ref }}{ }^{2}\left\{2\left[\frac{\gamma_{m}}{\gamma_{\text {ref }}}-\ln \left(1+\frac{\gamma_{m}}{\gamma_{\text {ref }}}\right)\right]-\frac{\left(\frac{\gamma_{m}}{\gamma_{\text {ref }}}\right)^{2}}{1+\frac{\gamma_{m}}{\gamma_{\text {ref }}}}\right\} \\
& \Delta \mathrm{W}_{\mathrm{MC}}=\left\{\frac{G_{\text {maks }}}{1+\frac{\gamma_{m}}{\gamma_{\text {ref }}}}\right\} \gamma_{m}^{2}\left(\frac{\gamma_{c}}{\gamma_{m}}-1\right)
\end{aligned}
$$

The maximum stored energy, $\mathrm{W}$ and the damping ratio, $\mathrm{D}$ in a cycle are given by equations below.

$$
\begin{aligned}
& W=\frac{1}{2} \tau_{m} \gamma_{c} \\
& D=\frac{1}{4 \pi} \frac{\Delta W_{H}+\Delta W_{M C}}{W} \\
& D=\frac{2}{\pi}\left\{2 \frac{1+\frac{\gamma_{m}}{\gamma_{\text {ref }}}}{\left(\frac{\gamma_{m}}{\gamma_{\text {ref }}}\right)^{2}}\left[\frac{\gamma_{m}}{\gamma_{r e f}}-\ln \left(1+\frac{\gamma_{m}}{\gamma_{\text {ref }}}\right)\right]\right\} \frac{1}{\frac{\gamma_{c}}{\gamma_{r e f}}}+\frac{2}{\pi} \frac{\left(\gamma_{c}-\gamma_{m}\right)}{\gamma_{c}}
\end{aligned}
$$

\subsection{Boundary conditions and damping}

The entire range of problems potentially encountered in geotechnical engineering exist in semi-infinite soil space, and the solutions are performed on the simulated finite media by discretizing with numerical methods. Thus the boundary conditions on the solution of the problem are crucial and need to be provided suitable with the surveyed wave propagation on infinite site conditions. In the dynamic analysis, advanced boundary conditions, improved to prevent the waves from being trapped inside the model without reflections that exist at the finite model borders, have been executed and given in Figure 9. The effectiveness of this type of energy-absorbing boundary has been demonstrated in both finite-difference and finite-element models (Cundall 2001). 


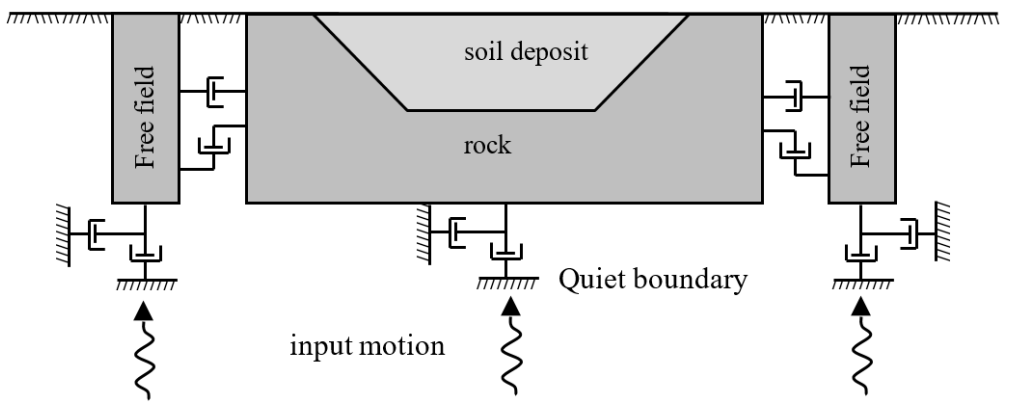

Figure 9. Boundary conditions and input motion excitation

At the bottom of the models, the quiet boundaries which prevent the reflection of outward propagating waves back into the model were assigned. On the lateral boundaries of the models, the nonreflecting free field boundaries were settled in a continuum finite difference scheme by coupling the main grid to the free-field grid by viscous dashpots. The assigned dashpots produce viscous normal and shear stress tractions along the model boundaries by given Equation 11-12.

$$
\begin{aligned}
& t_{n}=-\rho C_{p} v_{n} \\
& t_{s}=-\rho C_{s} v_{s}
\end{aligned}
$$

Where, $t_{n}, t_{s}$ normal and shear stresses traction, $\rho$ is the mass density, $C_{p}$ and $C_{s}$ are the pressure $(P)$ and shear $(S)$ wave velocities, $v_{n}$ and $v_{s}$ are the normal and shear components of velocity at the quiet boundary.

$$
\begin{aligned}
& F_{x}=-\rho C_{p}\left(v_{x} m_{-} v_{x} f f\right) A+F_{x} f f \\
& F_{y}=-\rho C_{s}\left(v_{y^{m} m_{-}} v_{y} f f\right) A+F_{y} f f \\
& F_{z}=-\rho C_{s}\left(v_{z^{m}} v_{z} f f\right) A+F_{z} f f
\end{aligned}
$$

Where, $F_{x}, F_{y}, F_{z}$, are gridpoint tractions of the free-field boundary, $v_{x}^{m}, v_{y}^{m} v_{z}^{m}$ are $\mathrm{x}, \mathrm{y}, \mathrm{z}$ velocity of gridpoint in the main grid at side boundary, $v_{x}^{f f}, v_{y}^{f f} v_{z}^{f f}$ are x, y velocity of gridpoint inside free field, $A$ is the area of influence of freefield gridpoint, $F_{x}^{f f}, F_{y}{ }_{y} f F_{z}^{f f}$ are free-field gridpoint force with contributions stresses of the free-field zones around the gridpoint (Itasca 2017).

\subsection{D and 1D models of the Gemlik basin}

The soil material in the basin has low shear wave velocity $\left(\mathrm{V}_{\mathrm{s}}\right)$ ranging from $160 \mathrm{~m} / \mathrm{s}$ to 220 in the near-surface, and the underlying layers get more rigid with increasing $V_{s}$ from $300 \mathrm{~m} / \mathrm{s}$ to $550 \mathrm{~m} / \mathrm{s}$ by the influence of the effective stress until the bedrock which has $\mathrm{V}_{\mathrm{s}}$ more than $750 \mathrm{~m} / \mathrm{s}$ at the base. The basin consists of alluvium deposits, old river and sea sediments composed of sandy-silty clay layers with medium to high plasticity index (PI) value change between 15-25\%. The significant $\mathrm{V}_{\mathrm{s}}$ contrast between deposits and bedrock is not very common in real basin conditions, even if the sediments are poorly consolidated soils overlying on bedrock, because of the increasing overburden pressure on the deeper layers (Bard and Bouchon 1980a; Zhu and Thambiratnam 2016) The layer descriptions, soil formations, shear strength parameters, and maximum modulus considered in sublayers are given in Table 1. 
Table 1. Specifications of the sub-layers and bedrock in the considered model.

\begin{tabular}{cccccccc}
\hline Layers description & Formation & $\begin{array}{c}\mathrm{c} \\
(\mathrm{kPa})\end{array}$ & $\begin{array}{c}\phi \\
\left({ }^{\circ}\right)\end{array}$ & $\begin{array}{c}\mathrm{V}_{\mathrm{s}} \\
(\mathrm{m} / \mathrm{s})\end{array}$ & $\begin{array}{c}\mathrm{G} \\
(\mathrm{MPa})\end{array}$ & $\begin{array}{c}\mathrm{K} \\
(\mathrm{MPa})\end{array}$ & $\begin{array}{c}\gamma \\
\left(\mathrm{kN} / \mathrm{m}^{3}\right)\end{array}$ \\
\hline $\begin{array}{c}\text { Silt clay (medium } \\
\text { plasticity) }\end{array}$ & $\begin{array}{c}\text { Quaternary } \\
\text { Alluvial }\end{array}$ & $50-80$ & 5 & $160-220$ & $40-90$ & $165-280$ & $17.0-18.0$ \\
$\begin{array}{c}\text { Sriassic } \\
\text { Sandy silty clay (medium } \\
\text { to high plasticity) }\end{array}$ & $\begin{array}{c}\text { Abadiye } \\
\text { Formation } \\
\text { Bedrock }\end{array}$ & $100-150$ & 10 & $300-550$ & $170-600$ & $475-1300$ & $19.0-20.0$ \\
\hline
\end{tabular}

c: cohesion, $\phi$ : shear strength angle, $V_{s}$ : shear wave velocity, G: shear modulus, K: bulk modulus, $\gamma$ : unit weight

Following the research topic, the preferred software allows investigating the wave propagation produced by such multiple physical phenomena as refraction, reflection, and resonance in infinite soil media and nonlinear soil behavior. In 2D and 1D analysis, when performing this type of analysis, the sizes of the discriminated element in the soil media needs to permit the transition of the applied seismic waves. Similarly, the smallest time step required for each calculation needs to ensure the highest frequency input motion propagation in the model. Only in these conditions, the motion can be transferred accurately to the surface throughout the defined finite media. Figure 10 presents free field boundary zones and the Finite Difference scheme of the Gemlik basins in 2D plane strain models, which are built and investigated by numerical analyses. In this way, plane waves propagate upward and sustain no distortion at the boundary because the free-field zones supply identical to those in an infinite model.

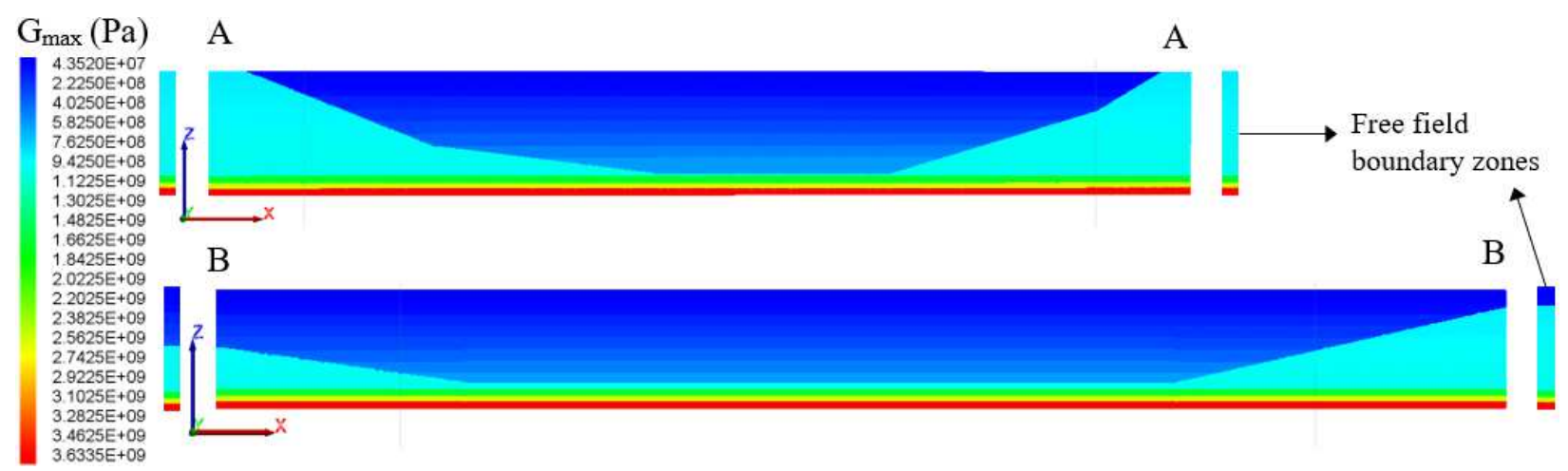

Figure 10. Finite Difference scheme of the numerical model of Gemlik basin in two directions

\subsection{Verification of the wave propagation}

In the study, a trapezoidal model proved by Kawase and Aki (1989) has been produced identically to validate the wave propagation. The same acceleration pattern has been captured across the model surface and given in Figure 11. The result of the Kawase and Aki (1989) analysis also has been tested by Iyisan and Khanbabazadeh (2014), Gil- Zepeda et al. (2003). The properties of the materials in the model have been defined by $1000-2500 \mathrm{~m} / \mathrm{s}$ shear wave velocities $\left(\mathrm{V}_{\mathrm{s}}\right)$, and the unit weight of materials have been taken as the same to provide a constant impedance value concerning the compared model. The shear and bulk modulus have been considered by taking the Poisson ratio as $1 / 3$. The propagation and distortion of the wave, the change of the wave characteristics in the material environment, and the 
spectrum distribution have been investigated using the wavelet. As the input motion, the Ricker pulse has provided the opportunity to definitely examine wave propagation for different frequency $\left(\mathrm{f}_{\mathrm{c}}\right)$ ranges and defined amplitudes $u(t)$. Consequently, it was settled that the numerical method and boundary conditions provide wave propagation, distraction, and reflection properly the same as the verification model.
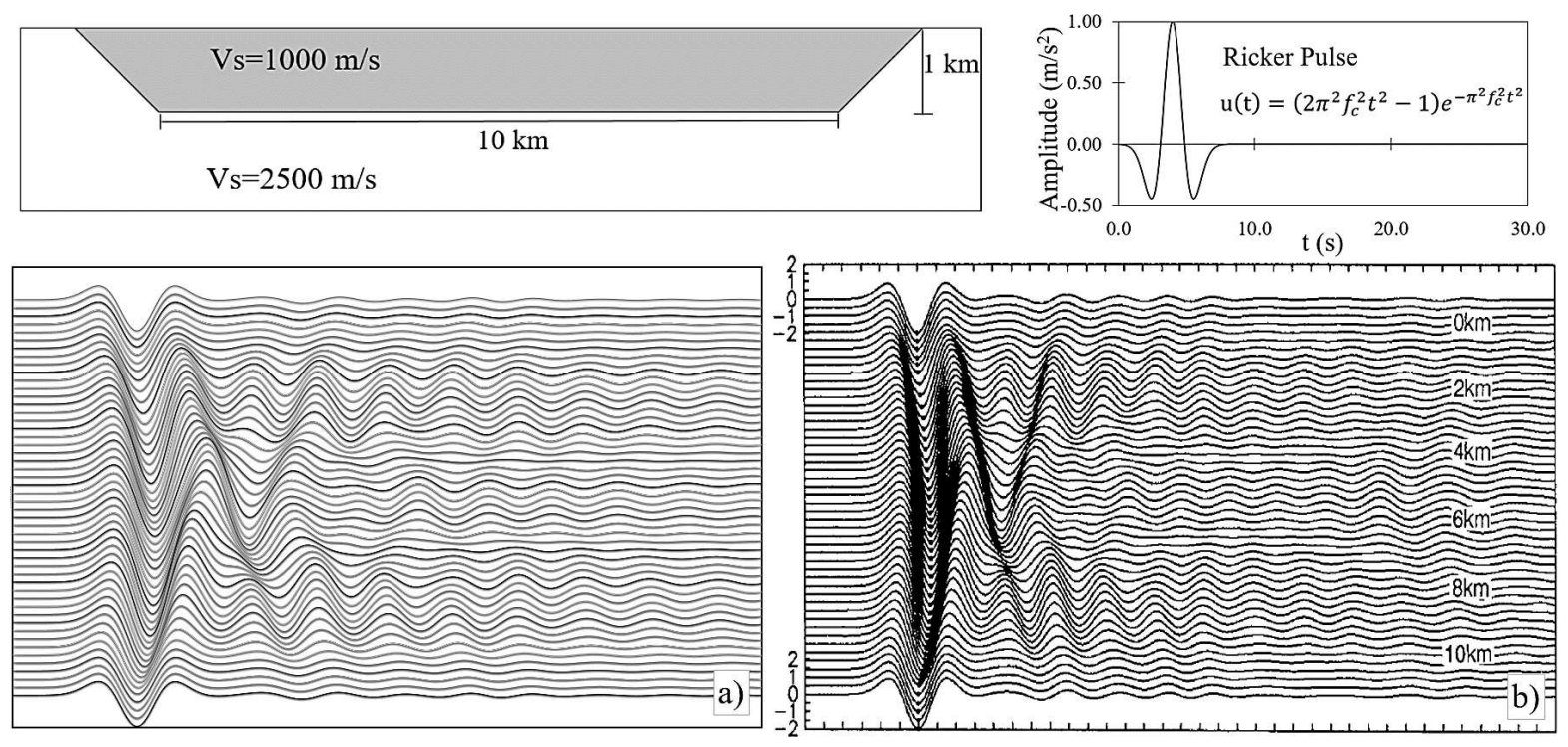

Figure 11. The specifications of the verification model and input motion (a) surface motion on the validation model in the study and (b) Kawase and Aki (1989)

In 2D plane strain and 1D soil coulumn models of the Gemlik basin have been built and investigated by the same numerical method. When generating the finite difference scheme, the maximum defined zone size $\left(l_{\max }\right)$ has been restricted to be equal to or less than $1 / 10$ or $1 / 8$ of the lowest wavelength $\left(\lambda_{\min }\right)$ defined in the model. In other words, it depends on the wavelength of the wave with maximum frequency $\left(f_{\max }\right)$ transmitted in the softest layer of the media. The zone dimensions are determined by the equations given below (Cundall 2001; Itasca 2017)

$$
\begin{aligned}
& \lambda_{\min } \leq \frac{V_{\sin }}{f_{\max }} \\
& \Delta l_{\text {max }} \leq \frac{\lambda_{\min }}{10}
\end{aligned}
$$

In the models, considering the assumed relations, the maximum zone sizes $(\Delta \operatorname{lmax})$ have been regulated as $1 \mathrm{~m}$ to $5 \mathrm{~m}$ by fitting to the shear wave velocity of the soil layers by seeing the earthquake records have the highest frequency components up to $15 \mathrm{~Hz}$.

\subsection{Input motions}

Computing response spectra for several varying strong ground motions and averaging them will lead to a smoother target spectrum. Producing such smoothed spectra is a significant step in improving a design spectrum. The ground motions are defined probabilistically as risk-targeted spectra by current seismic code provisions through the seismic hazard analyses. The results of hazard analyses are used to determine the site-specific Maximum Considered 
Earthquake $\left(\mathrm{MCE}_{\mathrm{R}}\right)$ and the Design Earthquake $\left(\mathrm{DE}_{\mathrm{R}}\right)$ spectrum, and also site-specific design acceleration parameters of short-period, SDS and 1-second period, SD1. The underlying methods of a site-specific ground motion analysis are necessarily highly technical and require a unique combination of geotechnical, earth science, and probabilistic expertise (FEMA 2020).

Across the basin models, both 1D and 2D site response analyses were performed under the sets of ground motion data which were selected by matching to the level of $\mathrm{MCE}_{R}$ spectrum and the level of $\mathrm{DE}_{\mathrm{R}}$ spectrum defined by exceedance probability of $2 \%$ in 50 years and $10 \%$ in 50 years, respectively in Figure 12. The input motion selection also considers near-fault and transition regions with given distances in the specification of the earthquakes in Table 2. In total, 22 earthquakes have been selected by matching to two levels of target spectra. Each strong ground motion set contains 11 earthquakes filtered by a $25 \mathrm{~Hz}$ low-pass filter and baseline corrected (Bommer and Acevedo 2004; Katsanos et al. 2010).

Table 2. The specifications of the selected earthquakes for $\mathrm{DE}_{\mathrm{R}}$ and $\mathrm{MCE} \mathrm{E}_{\mathrm{R}}$ levels

\begin{tabular}{|c|c|c|c|c|c|c|c|}
\hline Event & Station & Record & Component & $\begin{array}{l}\text { Magnitude } \\
\mathrm{M}_{\mathrm{w}}\end{array}$ & $\begin{array}{l}\text { Epicentral } \\
\text { Distance } \\
(\mathrm{km})\end{array}$ & $\begin{array}{l}\text { Hypocentral } \\
\text { Distance } \\
(\mathrm{km})\end{array}$ & $\begin{array}{l}\text { PGA } \\
(\mathrm{g})\end{array}$ \\
\hline$\overline{\mathrm{E} 1}$ & San Fernando, 1971 & Pacoima Dam & 164 & $6.6\left(\mathrm{M}_{\mathrm{w}}\right)$ & 11.9 & 17.6 & 1.22 \\
\hline E2 & San Fernando, 1971 & Pacoima Dam & 254 & $6.6\left(\mathrm{M}_{\mathrm{w}}\right)$ & 11.9 & 17.6 & 1.24 \\
\hline E3 & Tabas, Iran, 1978 & Tabas & $\mathrm{T}$ & $7.4\left(\mathrm{M}_{\mathrm{w}}\right)$ & 55.2 & 55.5 & 0.86 \\
\hline E4 & Loma Prieta, 1989 & Gilroy Array \#1 & 0 & $6.9\left(\mathrm{M}_{\mathrm{w}}\right)$ & 28.6 & 33.6 & 0.42 \\
\hline E5 & Northridge, 1994 & Pacoima Dam (Upper left) & 194 & $6.7\left(\mathrm{M}_{\mathrm{w}}\right)$ & 20.4 & 26.9 & 1.29 \\
\hline E6 & Duzce, Turkey,1999 & IRIGM 496 & $\mathrm{~N}-\mathrm{S}$ & $7.1\left(\mathrm{M}_{\mathrm{w}}\right)$ & 24.3 & 28.1 & 1.03 \\
\hline E7 & 1999 Kocaeli Earthquake & Kocaeli M. Station & E-W & $7.4\left(\mathrm{M}_{\mathrm{d}}\right)$ & 7.4 & 17.5 & 0.23 \\
\hline E8 & Parkfield, 2004 & Parkfield-Fault Zone 11 & 90 & $6.0\left(\mathrm{M}_{\mathrm{w}}\right)$ & 9.3 & 12.3 & 0.60 \\
\hline E9 & Parkfield, 2004 & Parkfield-Gold Hill 3W & 90 & $6.0\left(\mathrm{M}_{\mathrm{w}}\right)$ & 4.8 & 9.4 & 0.79 \\
\hline E10 & Parkfield, 2004 & Parkfield-Fault Zone 11 & 360 & $6.0\left(\mathrm{M}_{\mathrm{w}}\right)$ & 9.3 & 12.3 & 1.13 \\
\hline E11 & LAquila, Italy, 2009 & Aterno -Colle Grilli & 30 & $6.3\left(\mathrm{M}_{\mathrm{w}}\right)$ & 4.5 & 10.3 & 0.48 \\
\hline E12 & Nahanni, Canada, 1985 & Site 1 & 280 & $6.8(\mathrm{Mw})$ & 6.5 & 10.3 & 1.2 \\
\hline E13 & Nahanni, Canada, 1985 & Site 1 & 10 & $6.8(\mathrm{Mw})$ & 6.8 & 10.5 & 1.11 \\
\hline E14 & San Fernando, 1971 & Pacoima Dam & 164 & $6.6(\mathrm{Mw})$ & 11.9 & 17.6 & 1.22 \\
\hline E15 & Palm Springs, 1986 & Anza-Red Mountain & 360 & $6.1(\mathrm{Mw})$ & 46.2 & 47.5 & 0.12 \\
\hline E16 & Loma Prieta, 1989 & Gilroy Array \#1 & 0 & $6.9(\mathrm{Mw})$ & 28.6 & 33.6 & 0.42 \\
\hline E17 & Northridge, 1994 & Pacoima Dam (Upper left) & 194 & $6.7(\mathrm{Mw})$ & 20.4 & 26.9 & 1.29 \\
\hline E18 & Landers, 1992 & Lucerne & 260 & $7.3(\mathrm{Mw})$ & 44.0 & 44.6 & 0.73 \\
\hline E19 & Landers, 1992 & Lucerne & 345 & $7.3(\mathrm{Mw})$ & 44.0 & 44.6 & 0.79 \\
\hline E20 & Parkfield, 2004 & Parkfield-Fault Zone 11 & 360 & $6.0(\mathrm{Mw})$ & 9.3 & 12.3 & 1.13 \\
\hline E21 & Parkfield, 2004 & Parkfield-Fault Zone 11 & 90 & $6.0(\mathrm{Mw})$ & 9.3 & 12.3 & 0.60 \\
\hline E22 & Parkfield, 2004 & Parkfield-Gold Hill 3W & 90 & $6.0(\mathrm{Mw})$ & 4.8 & 9.4 & 0.79 \\
\hline
\end{tabular}



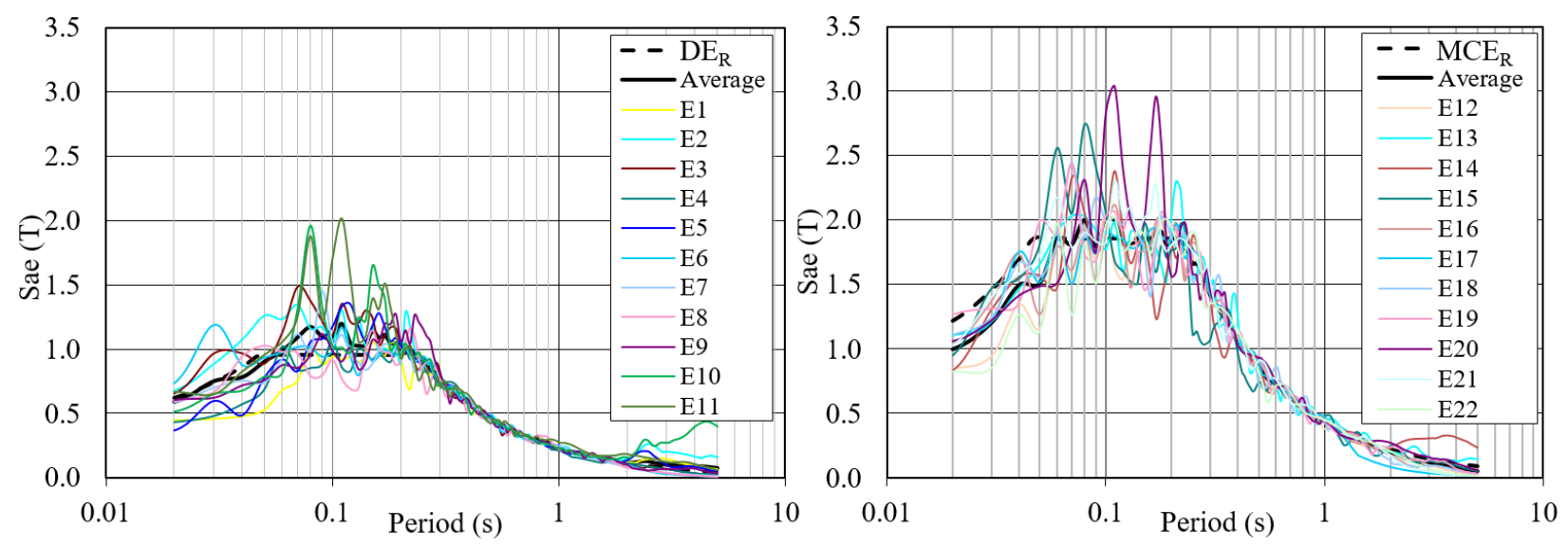

Figure 12. The selected earthquakes at seismic code-based target spectra of the site $(\xi=\% 5)$

\section{Results and Discussion}

\subsection{Comparison of 2D and 1D basin response}

Two seismic code-based levels of excitations have been performed into models to obtain the seismic response of the Gemlik basin in two directions. Thus, not only 2D and 1D models have been compared but also the maximum accelerations in input motions. In the stage of the assessment of the processed data, SH wave propagation in onedimensional soil columns created for each point that was selected with $50 \mathrm{~m}$ intervals throughout the basin surface was investigated by 1D analysis. In established 2D basin models, the effects of the stratigraphic two-dimensional discontinuity produced by refraction and reflection of SV waves were analyzed. Furthermore, the surface motions on 2D models have been recorded by synthetic seismographs located with equal intervals on the surface, similar to 1D analyses as $50 \mathrm{~m}$ intervals. Consequently, the spectral aggravation factors, $\mathrm{SAF}_{2 \mathrm{D} / 1 \mathrm{D}}=\mathrm{Sae}(\mathrm{T})_{2 \mathrm{D}} / \mathrm{Sae}(\mathrm{T})_{2 \mathrm{D}}$, have been defined as the ratio between the response spectrums of $2 \mathrm{D}$ and $1 \mathrm{D}$ models by considering locations and periods. A total of almost 1000 dynamic time history analyses has been performed and all results presented in detail.

On the other hand, the effect of rock outcrop distance to each other in the narrow section has also been studied by the earthquake waves produced on the surface. Accordingly, the ratio of the depth $(\mathrm{H})$ of the basin to its width $(\mathrm{L})$ is smaller than $\mathrm{H} / \mathrm{L}=1 / 10$ in contrary to the prior recent studies carried by Riga et al. (2016), Khanbabazadeh et al. (2018), and Zhu et al. (2018), in which the edge effect was examined.

The response spectra ratios calculated on the surface for different periods across the basin in 2D and 1D models are given in Figures 13-14. The surface acceleration spectra obtained in the artificial recorders s10, s16, s20, s24, s30, placed on the surface in the projections of the points where the changes of the edge slope at the bottom and the points of basin center, have been compared. In the A-A direction where the opposite sides of the basin are closer to each other in the E7 earthquake at the DER level, the aggravation factor increases to 2 in the basin center, especially at $\mathrm{T}=1 \mathrm{~s}$ period, while at the larger period of $\mathrm{T}=1.2 \mathrm{~s}$ reaches 1.5 values above the edge regions. In the earthquake E20 at MCER levels, the aggravation factor reaches the maximum value at the center in the $\mathrm{T}=1 \mathrm{~s}$ period, and similarly to DER level 
shifts to the edge region in a larger period. In lower periods, in $\mathrm{T}=0.2 \mathrm{~s}$ and $\mathrm{T}=0.4 \mathrm{~s}$, it is observed with multiple peak values of the highest aggravation factors occurring close to the edges of the basin in Figure 13.
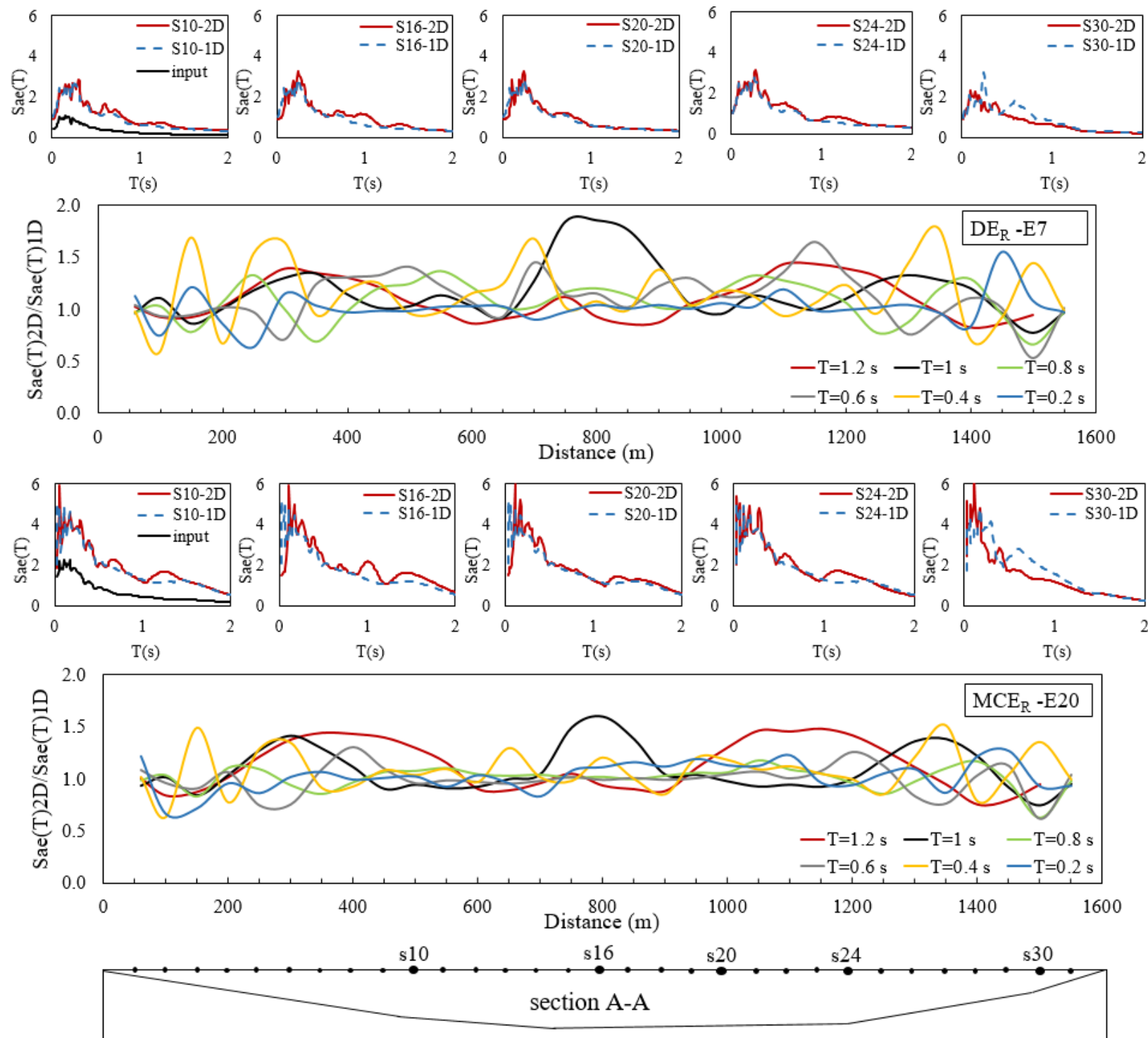

Figure 13. The variation of the response spectra and aggravation factors in $1 \mathrm{D}$ and $2 \mathrm{D}$ analyzes across the A-A section for levels of $\mathrm{DE}_{\mathrm{R}}$ and $\mathrm{MCE}_{\mathrm{R}}$

On the other hand, in the site response analysis conducted in the East-West direction, where the basin is wider than the other direction, and the edge slopes are approximately 10 degrees, smaller aggravation factors were obtained than the narrow section's values.

In Figure 14, the artificial recorders s11, s21, s31, s38, s45 have been used to compare the results of earthquakes E7 and E20. In the B-B section, where the inclination of the outcrop is relatively lower, the aggravation at high frequencies remains under 1.2, and the 1D and 2D response history analysis results in the center of the basin are almost the same, contrary to the A-A section. The highest aggravation factor values were obtained between 1.25-1.5 in the region close 
to the eastern edge. This situation confirms that in accordance with wave propagation phenomena previously described in the Semblat et al. (2005), Riga et al. (2016), and Zhu et al. (2016) studies, the increase in the width of the basin reduces the interference of the waves dispersed into the basin independently of the earthquake levels. In addition, the decreasing edge slope reduces the effects of the refraction, reflection, and shifting produced at high frequencies in the regions close to the edge.
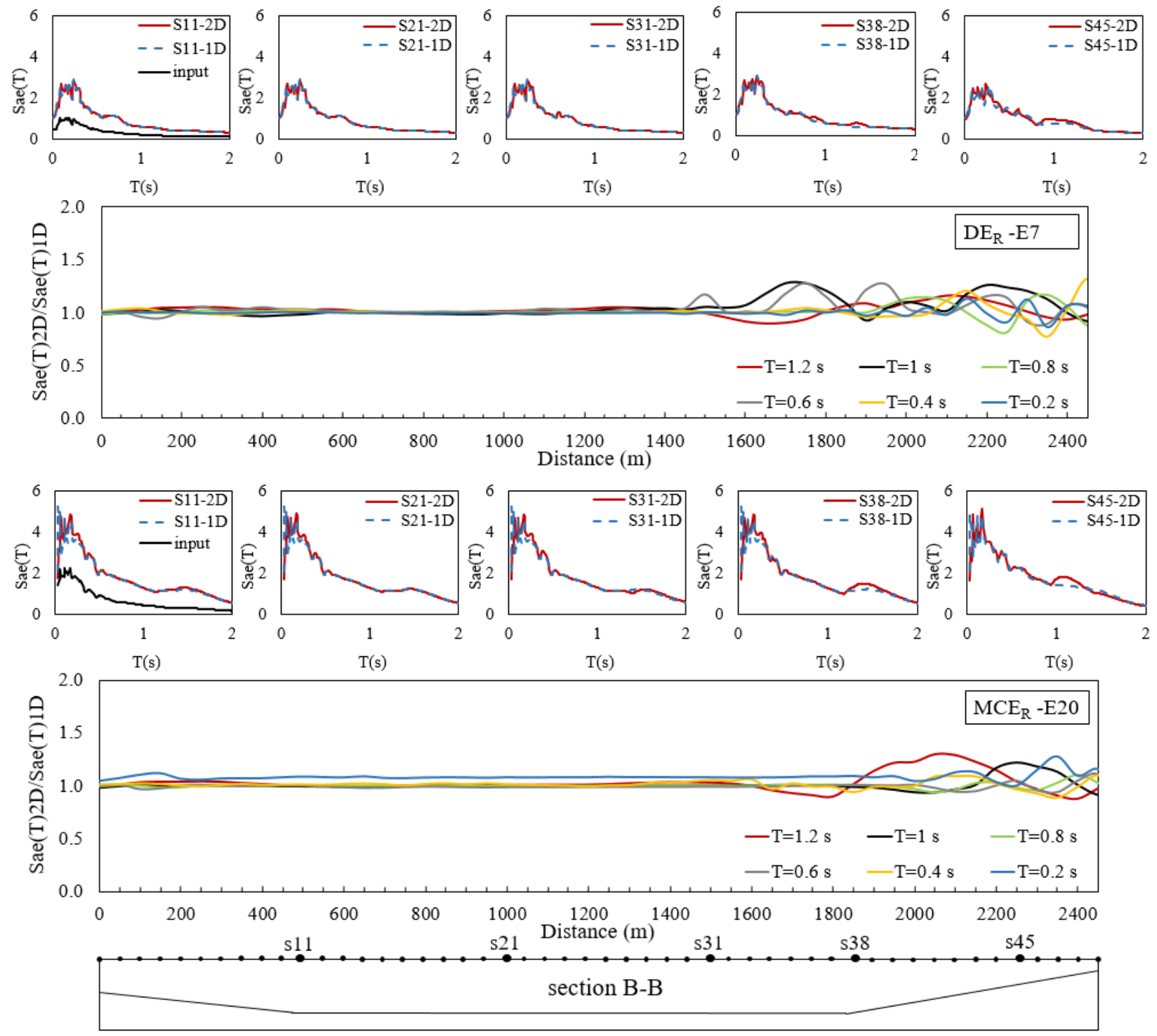

Figure 14. The variation of the response spectra and aggravation factors in $1 \mathrm{D}$ and $2 \mathrm{D}$ analyzes across the B-B section for levels of DER and MCER

\subsection{Maximum spectral aggravation factors for $D E_{R}$ and $M C E_{R}$}

The parameters need to satisfy the minimum requirements of the current seismic codes and must be those at the design earthquake or maximum considered earthquake shaking intensity. Site response in a basin can be significantly different 
from a result of the $1 \mathrm{D}$ analyses. Because the reflection, refraction, and resonance of the seismic waves in the basin soil media alter the surface motion or seismic demands on a structure, it is essential to represent the free field motion by further investigations accurately. The primary step of improving a design spectrum is developing a response spectrum with the average of the spectra obtained by taking into account sufficient diversities of earthquakes in sitespecific dynamic analyzes will lead to a smoother set of spectra. Comprehensive field experiments need to be done to investigate the basin structure to carry out such advanced analysis in 2D models. To select the suitable parameters of the soil constitutive models and examine wave propagation requires expertise in geotechnical and earthquake engineering, and evaluation of all analyzes results together requires numerical analysis and coding skills.

For this reason, in addition to the seismic code provisions, it is assumed that aggravation factor charts grouped according to the primary variables defining the soil classes and the geometric structure of a basin by making some assumptions with the procedure followed in several engineering calculations will help the application. Thus, it is considered that $1 \mathrm{D}$ analyzes that are currently used can be included in the basin response analyses by developing them with additional aggravation factors. In Figure 15-18, it is aimed to present the highest values of spectral aggravation by grouping to the strong ground motion levels consisting of 11 real earthquakes. Thus, both the effects of the differences in earthquake levels and lateral discontinuities that will cause to change in the aggravation factor depending on the location in the model are tried to be explained. It is illustrated in figures 15-16 that the narrow section of the Gemlik basin in the north-south direction increases the amplifications under the input motions at both levels that cannot be neglected. Considering the results given in Figures 17-18 in the east-west direction, this difference is interpreted as the superposition of the refracted and reflected seismic waves due to the interface which has a higher slope depending on location and frequency.

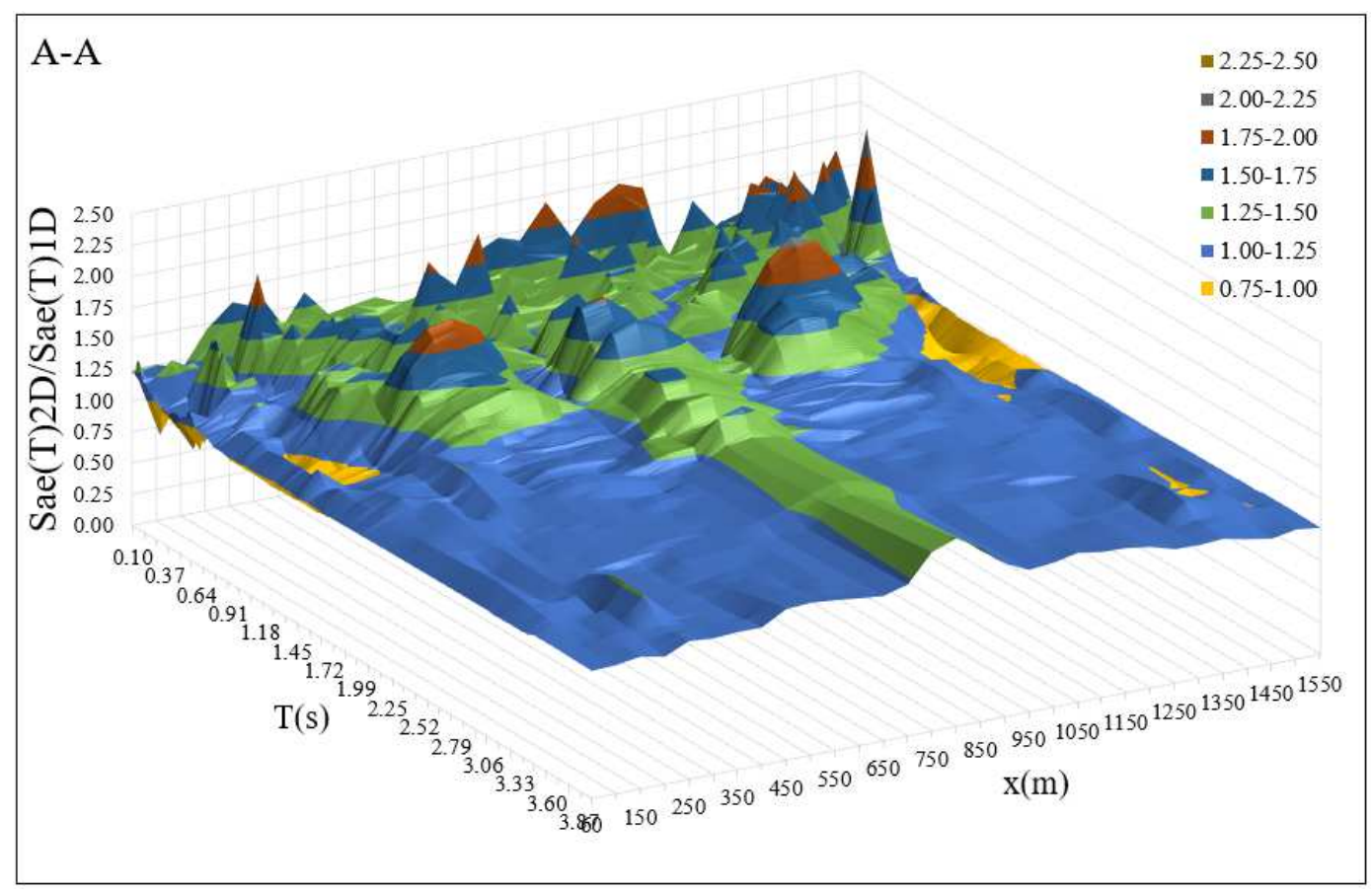

Figure 15. The maximum aggravation factors for MCER level in section A-A 


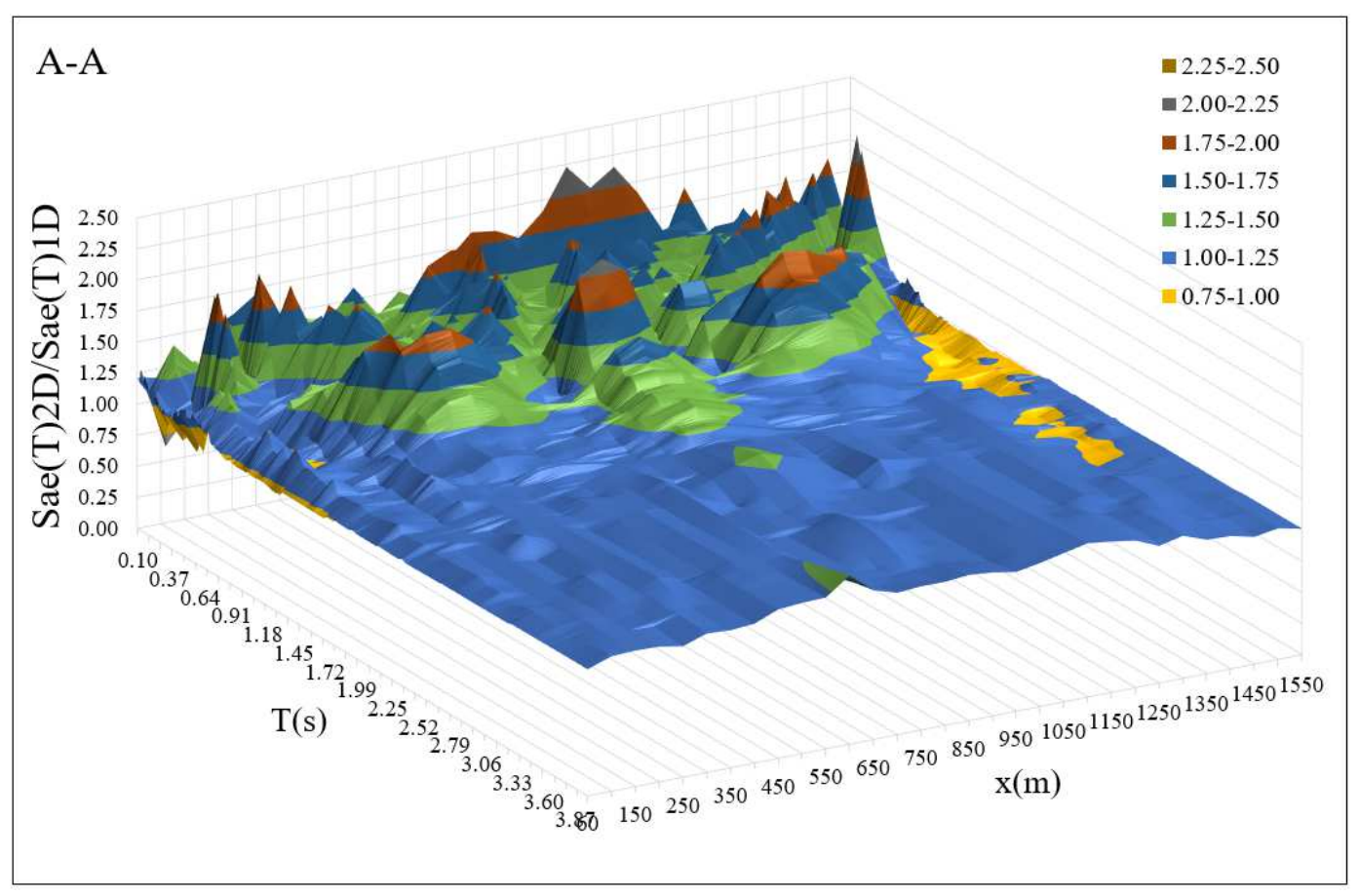

Figure 16. The maximum aggravation factors for $D_{R}$ level in section $A-A$

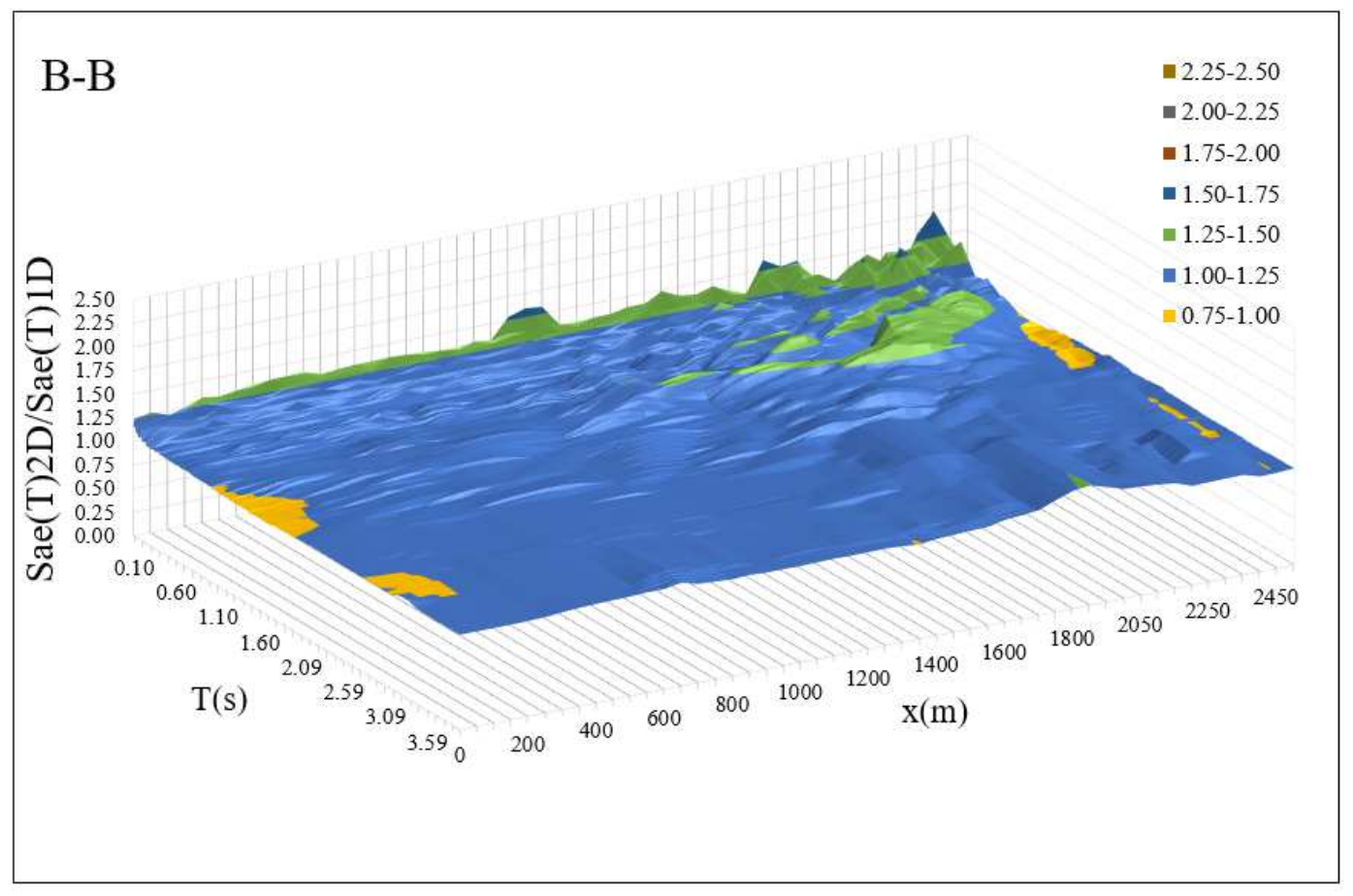

Figure 17. The maximum aggravation factors for $\mathrm{MCE}_{\mathrm{R}}$ level in section $\mathrm{B}-\mathrm{B}$ 


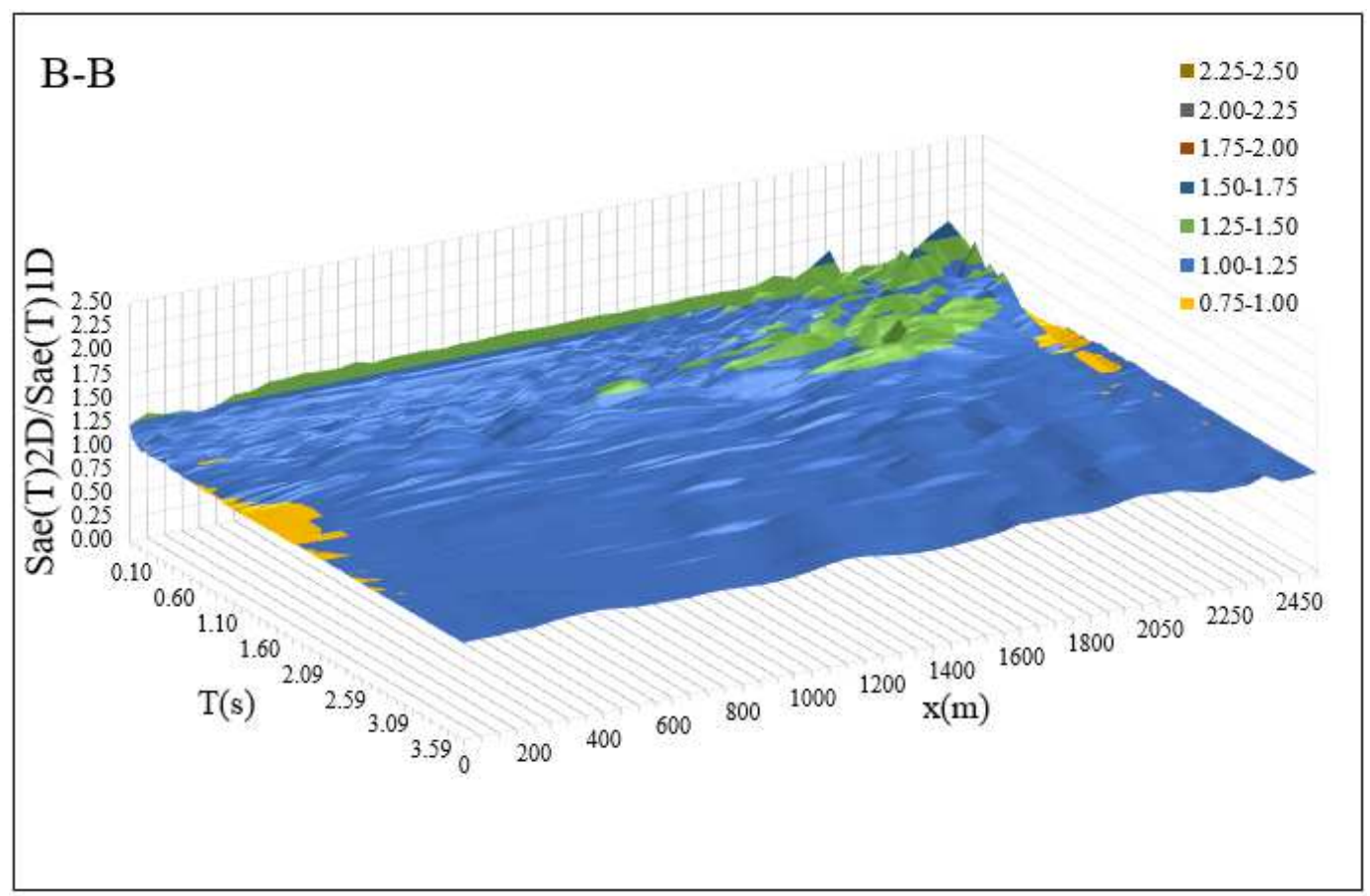

Figure 18. The maximum aggravation factors for $\mathrm{DE}_{\mathrm{R}}$ level in section $\mathrm{B}-\mathrm{B}$

On the other hand, it is seen that the maximum aggravation factors are between 1.25-1.5 values on the eastern edge of the B-B section. It is clear that the higher slope reflects the edge effects dominantly to the surface motions, and the behavior is getting similar to the $1 \mathrm{D}$ analysis in case the bedrock outcrop does not reach the surface regardless of earthquake level.

As the spectral aggravation factor charts unique for the Gemlik basin, it is intended the maximum values of the response spectra ratios are calculated by $1 \mathrm{D}$ and $2 \mathrm{D}$ time history analyses for 22 earthquakes in both directions at all points and each period. This spatial distribution of the maximum aggravation across the narrow direction can be seen in Figure 19.

At $1 \mathrm{~s}$ period, a restricted region in the center has aggravation factors greater than $2-2.25$, and the second peak is observed as $1.50-1.75$ at $1.2 \mathrm{~s}$ period while on the basin edges, the aggravations are noticed as $1.75-2.00$ between $1 \mathrm{~s}$ and $1.2 \mathrm{~s}$ with narrowing width of the basins. In Figure 20, totally different from the A-A section, it can be noticed that in section B-B, the maximum aggravations increase to $1.25-1.5$ in periods between $1 \mathrm{~s}-1.5 \mathrm{~s}$ only in the region close to the east edge. 


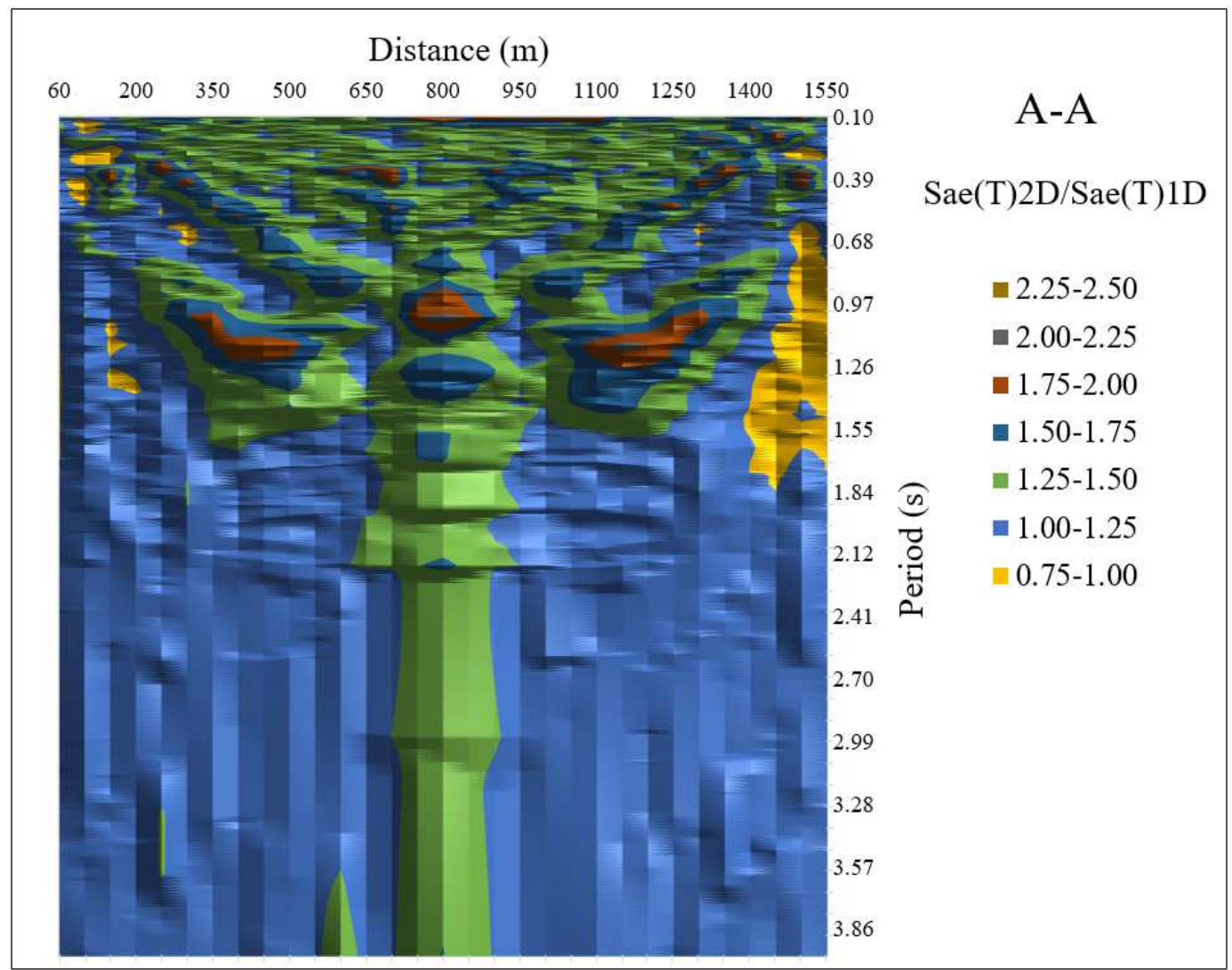

Figure 19. Maximum spectral aggravation factors for north-south direction in Gemlik basin

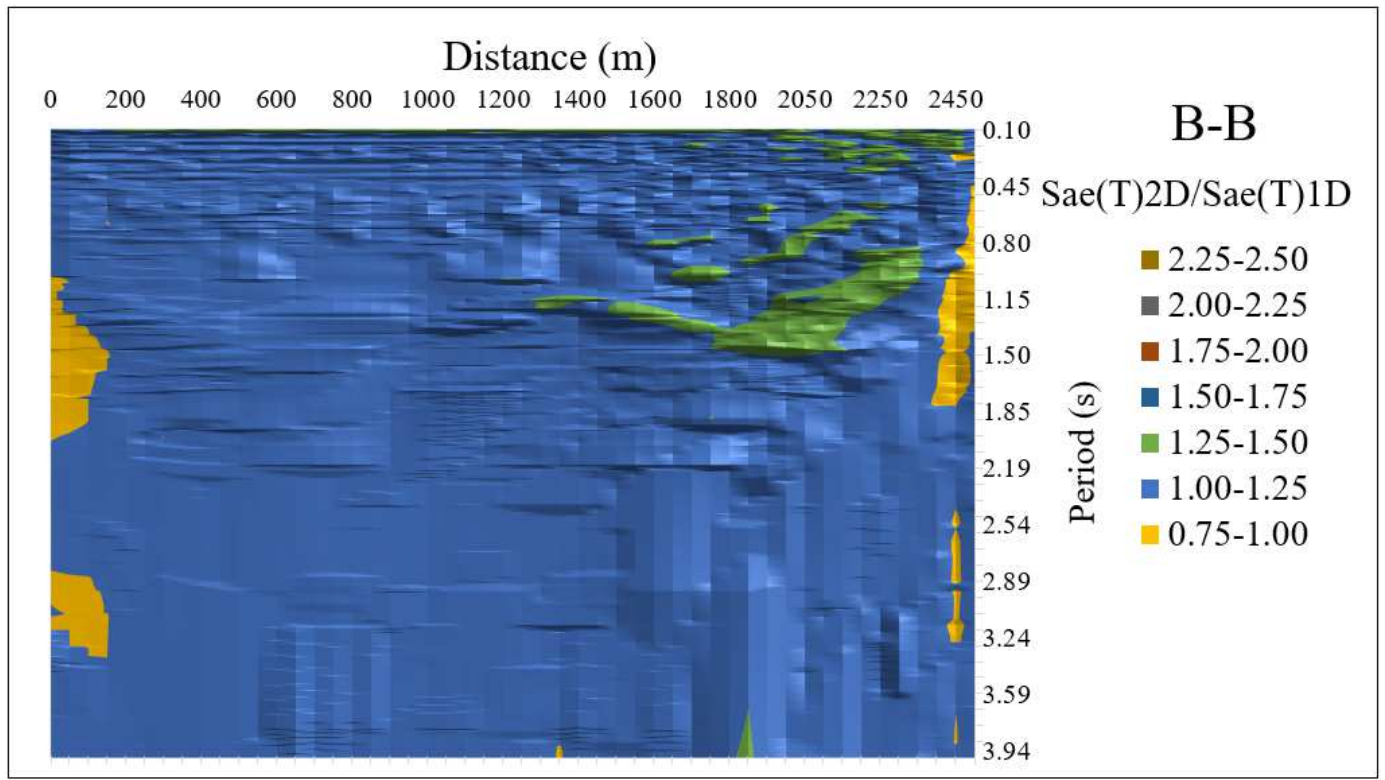

Figure 20. Maximum spectral aggravation factors for east-west direction in Gemlik basin 


\section{Conclusion}

In the Gemlik basin models created in the north-south and east-west directions by seismic tests and boring investigations, the aggravation factors have been defined by site-specific response analyzes performed considering the DER and MCER earthquake levels. The progression of the surface waves which are derived from both edges in the narrow direction of the Gemlik basin into the center of the basin, create higher amplification particularly at lower frequencies in 2D plane strain analyses with respect to results of the 1D soil column method. On the contrary, in the wider direction where the bedrock slope is lower, it is recognized that the aggravations take lower values only near the edge region, and the 2D and $1 \mathrm{D}$ analysis results get similar as they move away from the edge.

Consequently, the dynamic property of the soil deposit and earthquake characteristics have a remarkable effect on the strong ground motion. In contrast, in basins, the discontinuities of soil layers and distracted-interacted propagation of seismic waves have a more significant role in distributing the peak ground accelerations.

Particularly in alluvial sites, different regions along the basin surface are affected to various degrees. Therefore, the aggravation coefficients proposed for each specified region in the basin could be used more feasibly by calibrating to the 1D design spectrum. The multidimensional response analysis methods are necessitating a technical combination of geotechnical, earth science, and time-consuming process. Hence, the study method can develop basin-specific aggravating factors, and the suggested charts can be used with seismic code provisions. Finally, it is asserted that further studies that were numerically defining the regions where the basin affects mainly emerge and which periods are critical will significantly contribute to revealing the uncertainties about the subject.

\section{Declaration of Conflicting Interests and Data Availability Statement}

On behalf of all authors, the corresponding author states that there is no potential conflict of interest with respect to the research, authorship, and/or publication of this article. All data of the analyses and models or codes that clarify this investigation's findings are available from the corresponding author upon reasonable request.

\section{Acknowledgments and Funding}

The authors gratefully acknowledge the financial support provided by the Scientific and Technological Research Council of Turkey (TUBITAK) under the grant 218M959 project titled "Determination of Spectral Aggravation Factors in Alluvial Basins by Nonlinear Numerical Analysis.”

\section{References}

Abraham JR, Smerzini C, Paolucci R, Lai CG (2016) Numerical study on basin-edge effects in the seismic response of the Gubbio valley, Central Italy. Bull Earthq Eng. doi: 10.1007/s10518-016-9890-y

Aki K, Larner K (1970) Surface motion of a layered medium having an irregular interface due to incident plane SH waves. J Geophys Res. 75, 933-954

Bakir BS, Özkan MY, and Ciliz S (2002) Effects of Basin Edge on the Distribution of Damage in 1995 Dinar Turkey Earthquake. Soil Dyn Earthq Eng, 22 (4), 335-45. doi: 10.1016/S0267-7261(02)00015-5 
Bard P. and Bouchon M. (1980a) The Seismic Response of Sediment-Filled Valleys. Part 1. The Case of Incident SH Waves. Bull Seismol Soc Am. 70 (4): 1263-86

Bard PY, Chafcub E, Pitilakis K, Makra K, Gelagoti O, Ktenidou J, Riga E, Moczo P and Kristek J (2010) Network of European Research Infrastructures for Earthquake Risk Assessment and Migitation

Bielak J, Jifeng X and Ghattas O (1999) Earthquake Ground Motion and Structural Response in Alluvial Valleys. J Geotech Geoenvironmental Eng. 125 (5): 413-23

Bommer JJ and Acevedo AB (2004) The use of real earthquake accelerograms as input to dynamic analysis. J Earthq Eng. 8(January 2015), pp. 43-91. doi: 10.1080/13632460409350521

Chávez-García FJ, Faccioli E (2000) Complex site effects and building codes: making the leap. J Seismol. 4:23-40

Chávez-García FJ et al. (2018) Site effects using methods based on lateral homogeneity and laterally heterogeneous media: An impossible marriage? Bull Earthq Eng. doi: 10.1007/s10518-017-0296-2

Cipta A, Cummins P, Irsyam M and Hidayati S (2018) Basin resonance and seismic hazard in Jakarta, Indonesia. Geosciences, 8(4), 128. doi: 10.3390/geosciences8040128

Cundall PA (2001) FLAC Manual: A Computer Program for Fast Lagrangian Analysis of Continua (First Revision) Minneapolis, Minnesota, USA

Emre MH, Iyisan R, Yamanaka H (2018) Basin Edge Effect on Seismic Ground Response: A Parametric Study for Duzce Basin Case, Turkey. Arab J Sci Eng. 43 (4): 2069-81. doi: 10.1007/s13369-017-2971-7

Federal Emergency Management Agency (2020) NEHRP Recommended Seismic Provisions for New Buildings and Other Structures-Volume I: Part 1 Provisions, Part 2 Commentary-FEMA P.2082-1, Building Seismic Safety Council. Washington, D.C.

Gil-Zepeda SA, Montalvo-Arrieta JC, Vai R, Sanchez-Sesma FJ (2003) A hybrid indirect boundary element-discrete wave number method applied to simulate the seismic response of stratified alluvial valleys. Soil Dyn Earthq Eng. 23:77-86. doi: 10.1016/S0267-7261(02)00092-1

Graves RW, Pitarka A and Somerville PG (1998) Ground-Motion Amplification in the Santa Monica Area: Effects of Shallow Basin-Edge Structure. Bull Seismol Soc Am. 88 (5): 1224-42

Imai T (1977) P-and S-wave velocities of the ground in Japan, Proc.9th Int. Conf. on Soil Mechanics and Foundation Engineering, vol 2, 127-32

Itasca Consulting Group (2017) FLAC3D Manual- Fast Lagrangian Analysis of Continua in Three-Dimensions. Minneapolis

Iyisan R (1996) Correlations between shear wave velocity and in-situ penetration test results, Tech. J. Chamber Civil Eng. Turkey, 7, 1187-99 (in Turkish)

Iyisan R and Haşal ME (2011) The Basin Edge Effect on Dynamic Response: Dinar Basin Model. IMO Teknik Dergi. 5559-5578 (in Turkish)

Iyisan R and Khanbabazadeh H (2013) A numerical study on the basin edge effect on soil amplification. Bull Earthq Eng. 11:1305-23 
Japan Road Association (JRA) (1980) Specification and interpretation of bridge design for highway-part V: Resilient design

Katsanos EI, Sextos AG and Manolis GD (2010) Selection of earthquake ground motion records: A state-of-the-art review from a structural engineering perspective. Soil Dyn Earthq Eng. Vol. 30(4), pp. 157-169. doi:10.1016/j.soildyn.2009.10.005

Kawase H (1996) The cause of the damage belt in Kobe. the basin-edge effect, constructive interference of the direct $\mathrm{S}$ wave with the basin-induced diffracted/Rayleigh waves. Seismol Res Lett. 67, (5), 25-35

Kawase H and Aki K (1989) A Study of the Response of a Soft Basin for Incident S, P, and Rayleigh Waves with Special Reference to the Long Duration Observed in Mexico City. Bull Seismol Soc Am. 79 (5): 1361-82

Khanbabazadeh H, Iyisan R (2014) A numerical study on the 2D behavior of the single and layered clayey basins, Bull Earthq Eng. 12(4), 1515-1536. doi: 10.1007/s10518-014-9590-4

Khanbabazadeh H, Iyisan R, Ansal A and Zulfikar C. (2018) Nonlinear dynamic behavior of the basins with 2D bedrock. Soil Dyn Earthq Eng. vol. 107, no. August 2017, pp. 108-115. doi: 10.1016/j.soildyn.2018.01.011

Khanbabazadeh H, Iyisan R, Ansal A, Hasal ME (2016) 2D nonlinear seismic response of the Dinar basin, TURKEY. Soil Dyn Earthq Eng. 89: 5-11. doi: 10.1016/j.soildyn.2016.07.021

Khanbabazadeh H, Hasal ME and Iyisan R (2019) 2D Seismic Response of the Duzce Basin, Turkey. Soil Dyn Earthq Eng. https://doi.org/10.1016/j.soildyn.2019.105754

King JL, Tucker BE (1984) Observed Variations of Earthquake Motion Across a Sediment-Filled Basin, Bull. Seismol. Soc. Am. vol. 74, no. 1, pp. 137-151

Makra K and Chávez-García FJ (2016) Site effects in 3D basins using 1D and 2D models: an evaluation of the differences based on simulations of the seismic response of Euroseistest. Bull Earthq Eng. vol. 14, no. 4, pp. 11771194. doi: 10.1007/s10518-015-9862-7

Moczo P, Kristek J, Bard PY et al. (2018) Key structural parameters affecting earthquake ground motion in 2D and 3D sedimentary structures. Bull Earthquake Eng. 16, 2421-2450 https://doi.org/10.1007/s10518-018-0345-5

Okada H and Suto K (2003) The Microtremor Survey Method, The Microtremor Survey Method. doi: $10.1190 / 1.9781560801740$

Okay AI and Göncüoğlu MC (2004) The Karakaya Complex: A review of data and concepts. Turkish Journal of Earth Sciences, 13, 77-95

Özaslan B, Haşal ME, Khanbabazadeh H, Akbaş M and İyisan R, (2020) Dynamic Response Analysis of

Trapezoidal Basins on Numerical Models. IOP Conference Series: Materials Science and Engineering 960 (4) https://doi.org/10.1088/1757-899X/960/4/042048

Papageorgiou AS and Kim J (1991) Study of the Propagation and Amplification of Seismic Waves in Caracas Valley with Reference to the 29 July 1967 Earthquake: SH Waves. Bull Seismol Soc Am. 81 (6): 2214-33

Pei D and Papageorgiou AS (1996) Locally Generated Surface Waves in Santa Clara Valley: Analysis of Observations and Numerical Simulation. Earthq Eng Struct Dyn. 25 (1): 47-63

Riga E, Makra K and Pitilakis K (2016) Aggravation factors for seismic response of sedimentary basins: A codeoriented parametric study. Soil Dyn. Earthq. Eng. vol. 91, pp. 116-132, Dec. doi: 10.1016/j.soildyn.2016.09.048 
Semblat, J. F., M. Kham, E. Parara, P. Y. Bard, K. Pitilakis, K. Makra, and Raptakis, D. (2005) Seismic Wave Amplification: Basin Geometry vs Soil Layering. Soil Dyn Earthq Eng. 25 (7-10): 529-38. doi: 10.1016/j.soildyn.2004.11.003

Smith WD (1975) The application of finite element analysis to body wave propagation problems, Geophys. J. 42, 747768

Somerville PG and Graves RW (2003) Characterization of Earthquake Strong Ground Motion. Pure Appl Geophys. 160 (10-11): 1811-28. doi: 10.1007/s00024-003-2407-z

Wong HL and Trifunac MD (1974) Scattering of Plane SH Waves by a Semi-Elliptical Canyon. Earthq Eng Struct Dyn. vol. 3, 157-169

Yamanaka H (1989) Study on seismic wave propagation in sedimentary layers with irregular interfaces. Dissertation, Tokyo Institute of Technology, Japan

Yamanaka H (2005) Comparison of Performance of Heuristic Search Methods for Phase Velocity Inversion in Shallow Surface Wave Method. J Environ Eng Geophys. 10 (2): 163-73. https://doi.org/10.2113/JEEG10.2.163

Yamanaka H and Ishida H (1996) Application of Genetic Algorithms to an Inversion of Surface-Wave Dispersion Data. Bull Seismol Soc Am. vol. 86, pp. 436-444

Zhang B and Papageorgiou AS (1996) Simulation of the response of the Marina District Basin, San Francisco, California, to the 1989 Loma Prieta Earthquake. Bull Seismol Soc Am. 86 (5): 1382-1400

Zhu C and Thambiratnam D (2016) Interaction of geometry and mechanical property of trapezoidal sedimentary basins with incident SH waves. Bull Earthq Eng. 14(11), pp. 2977-3002. doi: 10.1007/s10518-016-9938-z

Zhu C, Thambiratnam D, Gallage C (2018) Statistical analysis of the additional amplification in deep basins relative to the 1D approach, Soil Dyn. Earthq. Eng., vol. 104, pp. 296-306, Jan. doi: 10.1016/j.soildyn.2017.09.003 
Figures

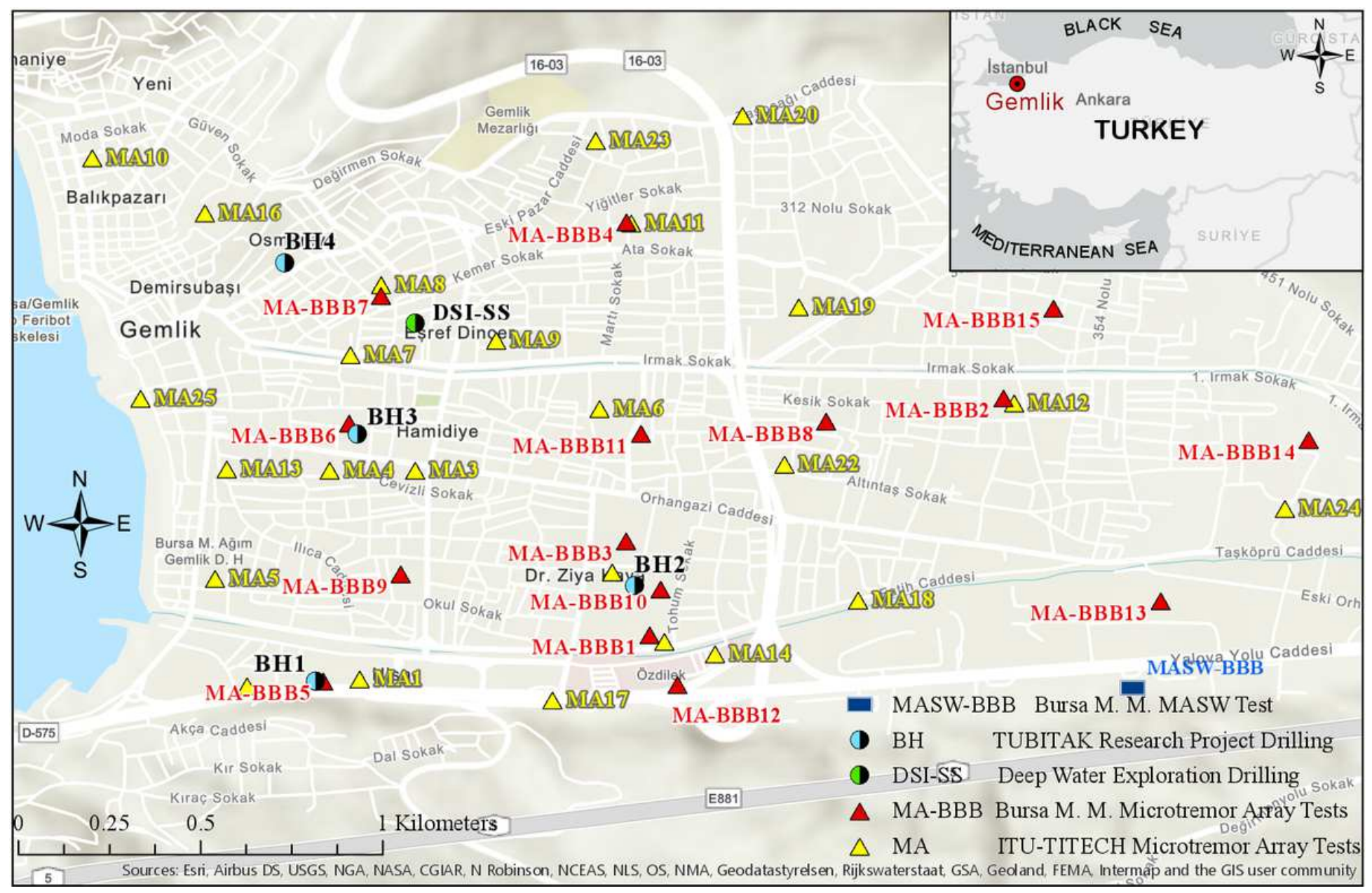

\section{Figure 1}

Site investigations in Gemlik district, Turkey. Note: The designations employed and the presentation of the material on this map do not imply the expression of any opinion whatsoever on the part of Research Square concerning the legal status of any country, territory, city or area or of its authorities, or concerning the delimitation of its frontiers or boundaries. This map has been provided by the authors. 


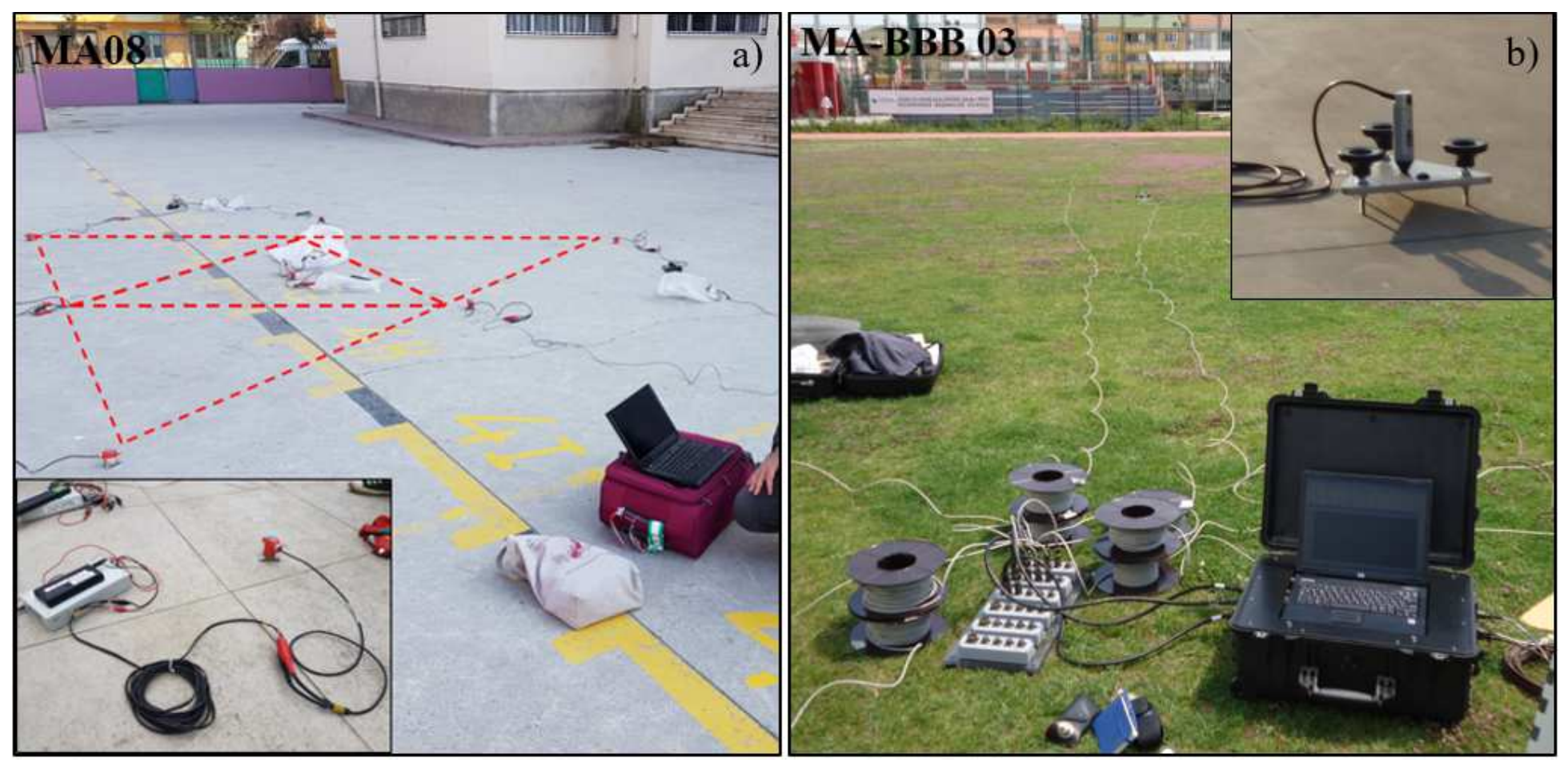

Figure 2

Array plan and two different microtremor sets a) ITU-TITECH MA measurements, b) Bursa Metropolitan Municipality MA-BBB measurements 


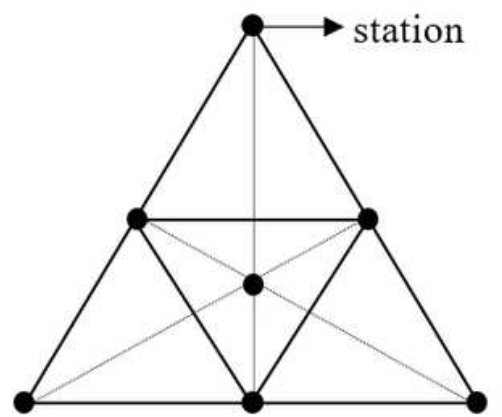

Microtremor array method

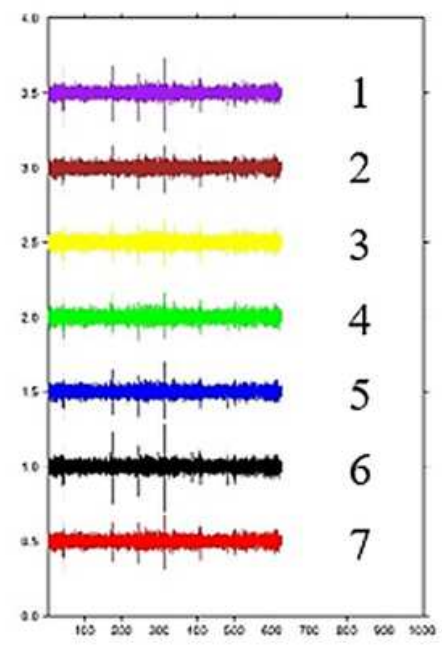

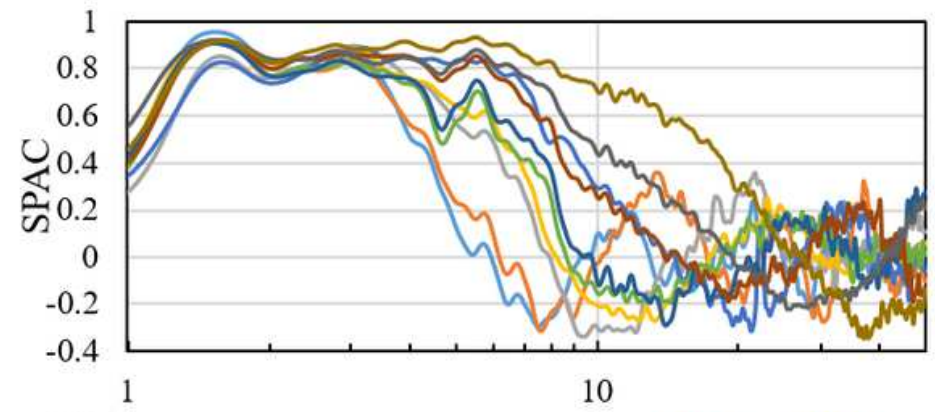

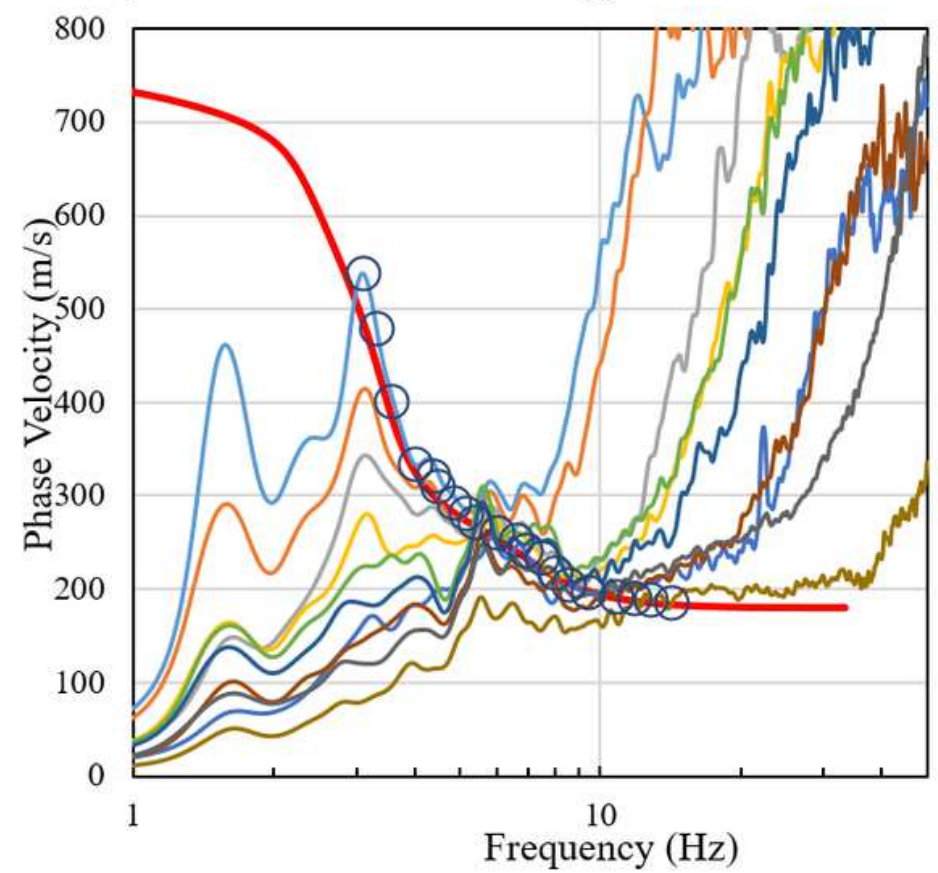

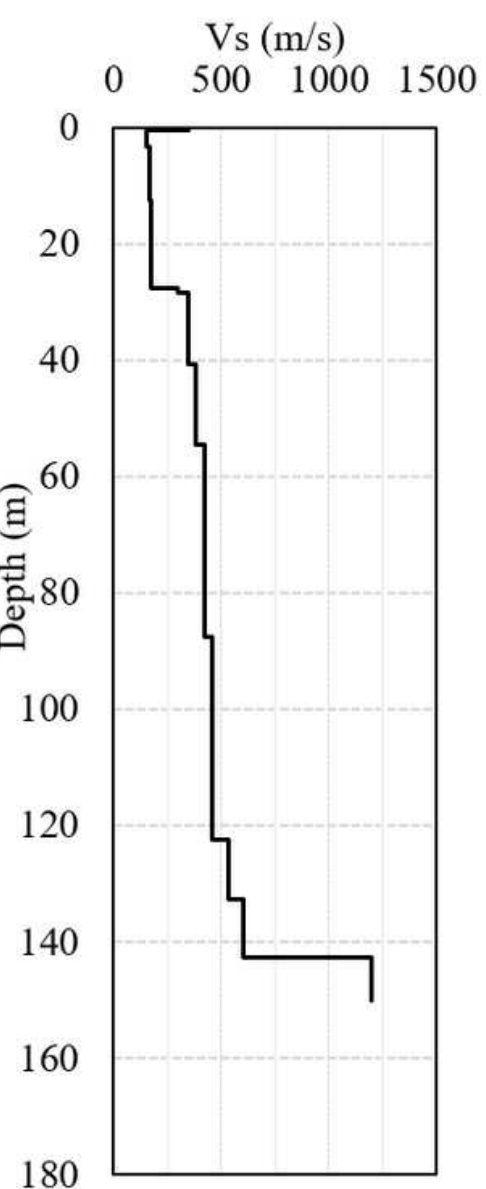

Figure 3

Array measurement plan, data set, phase velocity and SPAC coefficients and Vs profile 


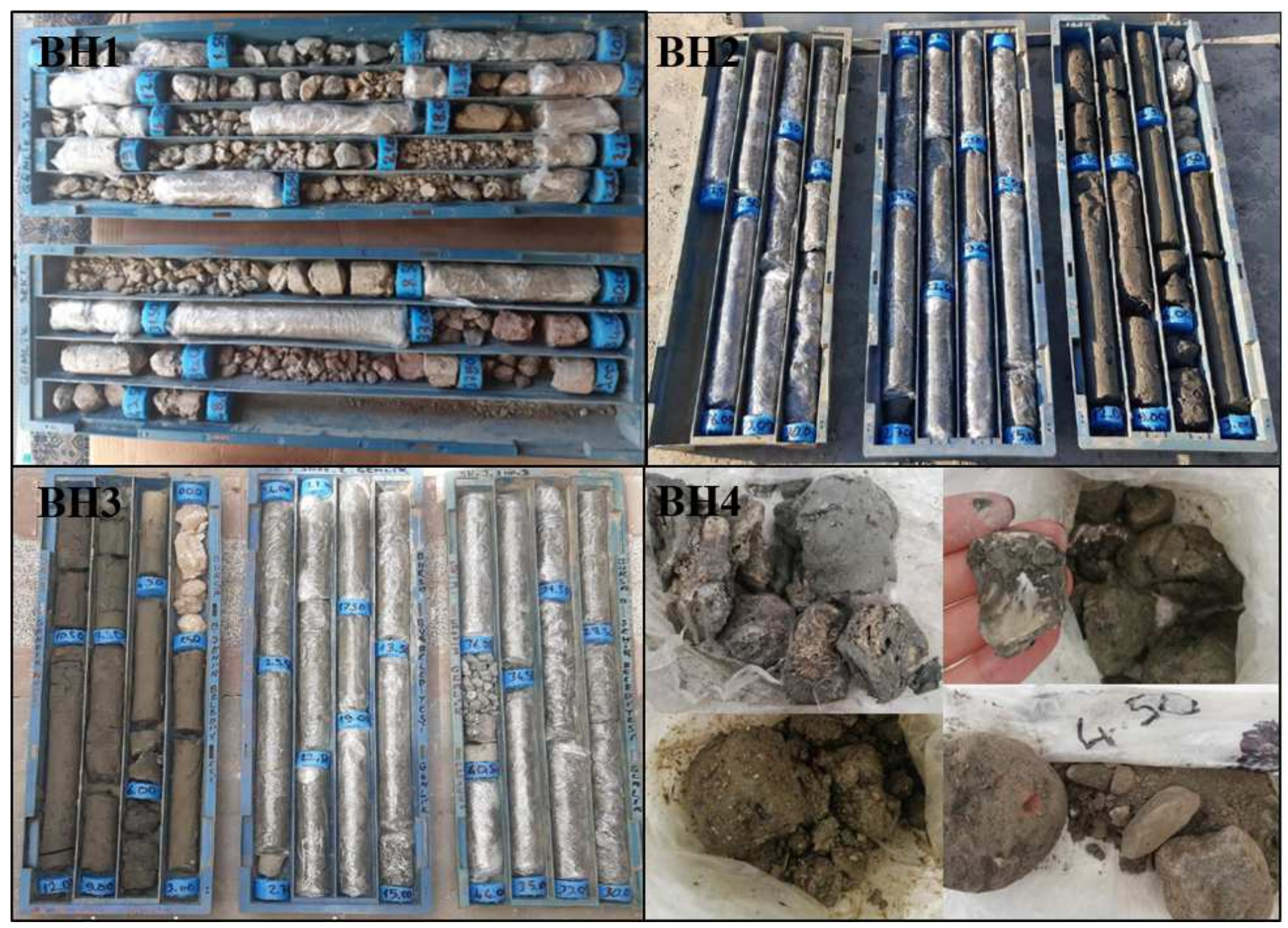

Figure 4

The alluvial deposits in the main lithology discovered by borings $\mathrm{BH} 1-\mathrm{BH} 4$ in Gemlik basin 


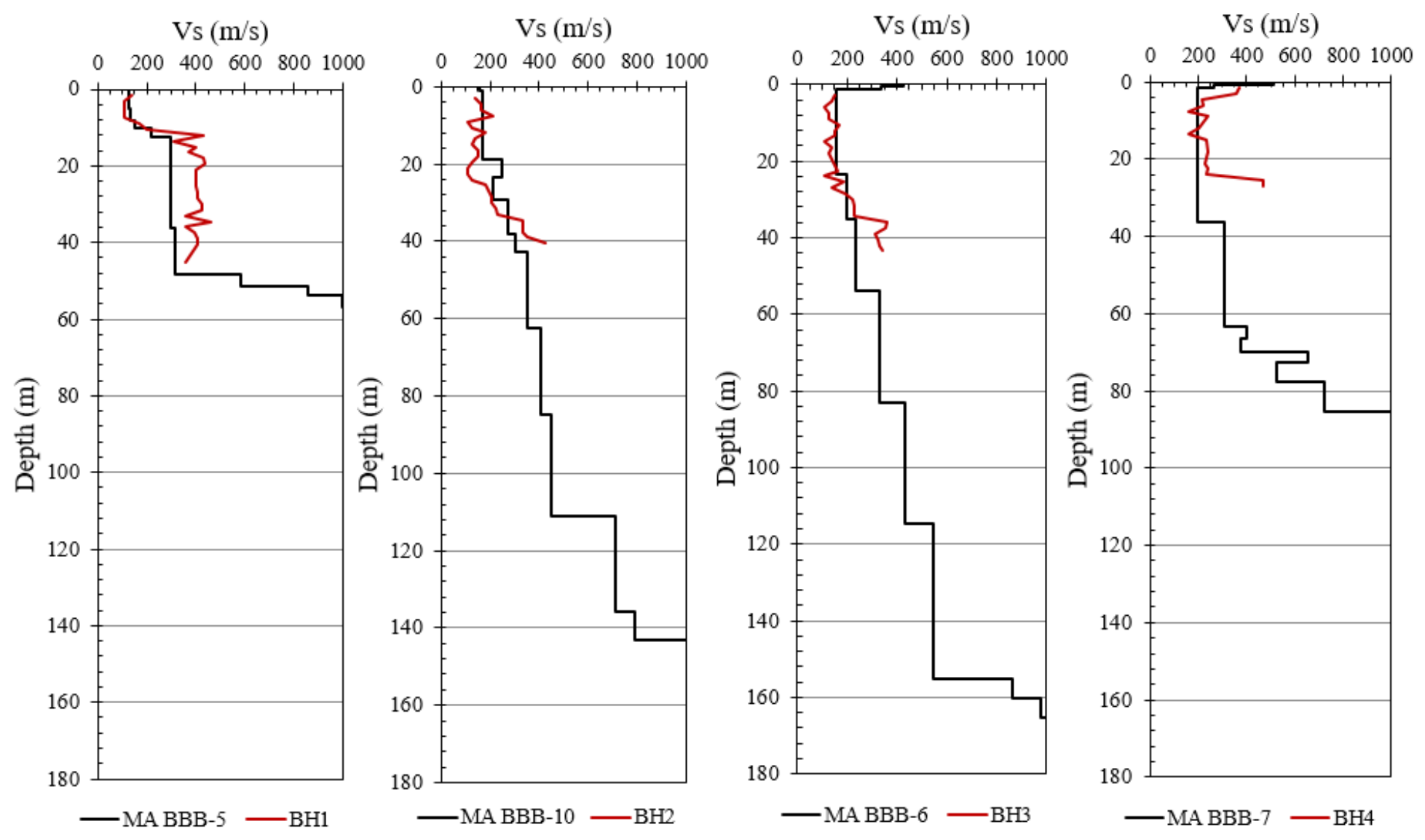

Figure 5

Comparison of the shear wave profiles of seismic test and SPT

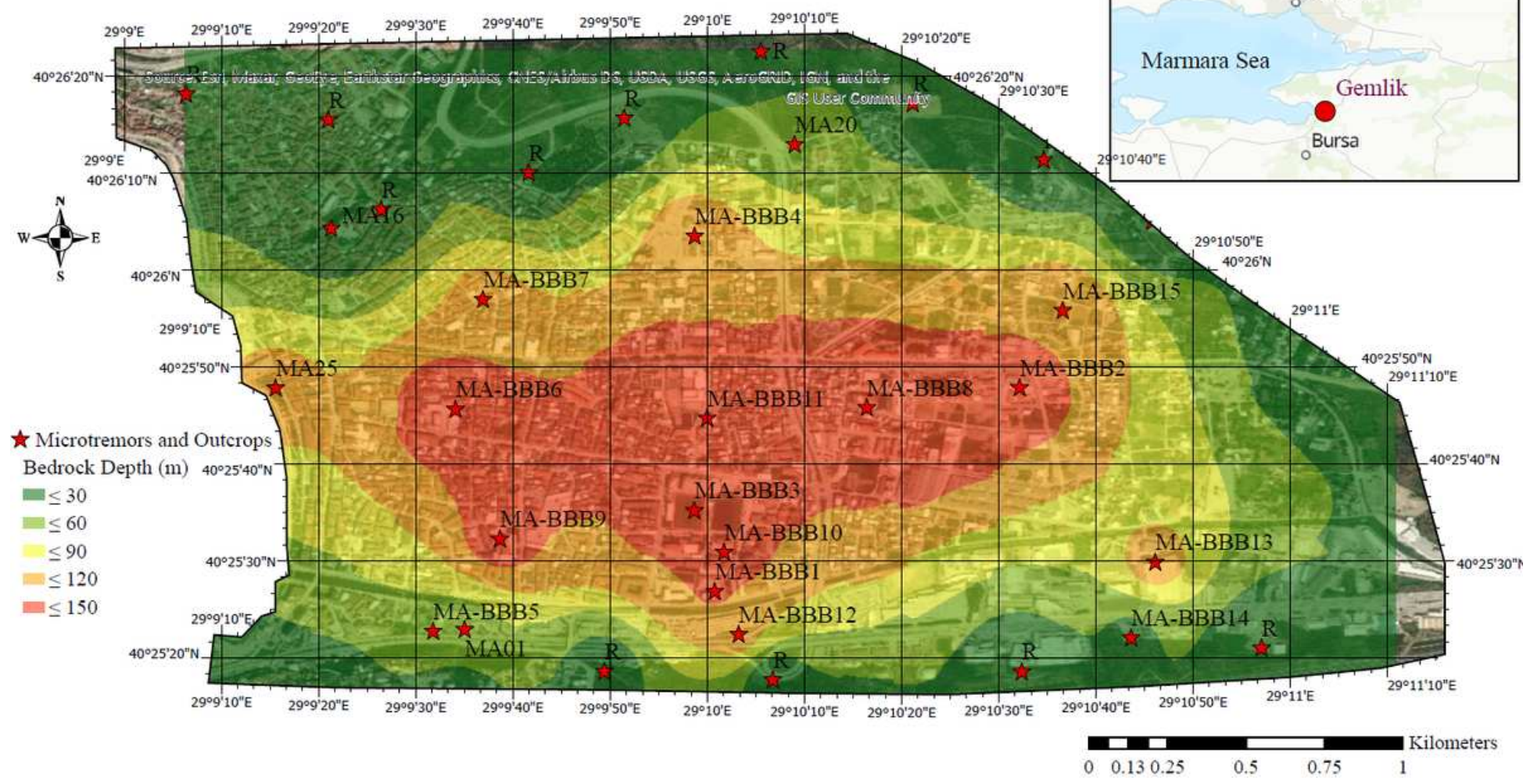




\section{Figure 6}

Bedrock depth by shear wave velocities in Gemlik basin. Note: The designations employed and the presentation of the material on this map do not imply the expression of any opinion whatsoever on the part of Research Square concerning the legal status of any country, territory, city or area or of its authorities, or concerning the delimitation of its frontiers or boundaries. This map has been provided by the authors.

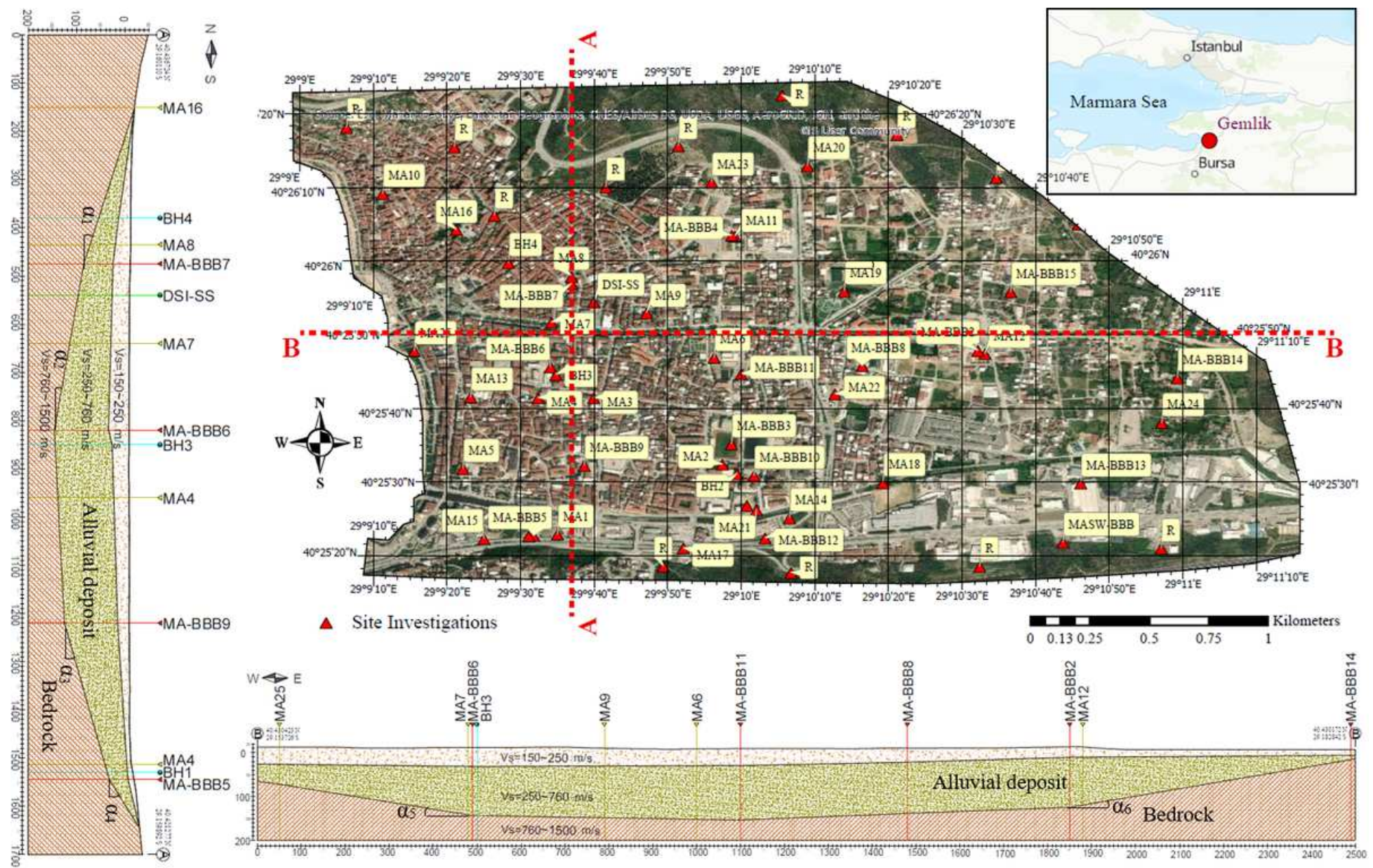

Figure 7

The variation of the bedrock and layers inclinations in A-A and B-B sections and the positions of the site investigations. Note: The designations employed and the presentation of the material on this map do not imply the expression of any opinion whatsoever on the part of Research Square concerning the legal status of any country, territory, city or area or of its authorities, or concerning the delimitation of its frontiers or boundaries. This map has been provided by the authors. 


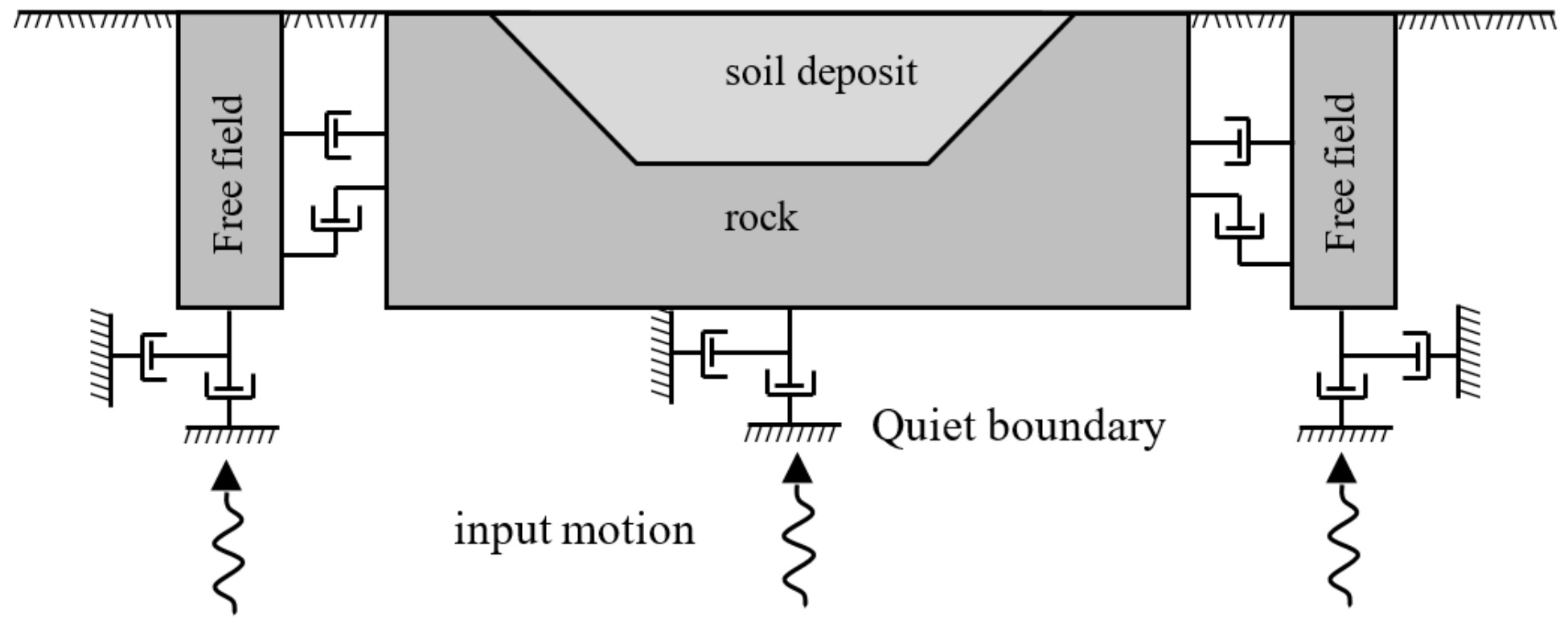

Figure 9

Boundary conditions and input motion excitation

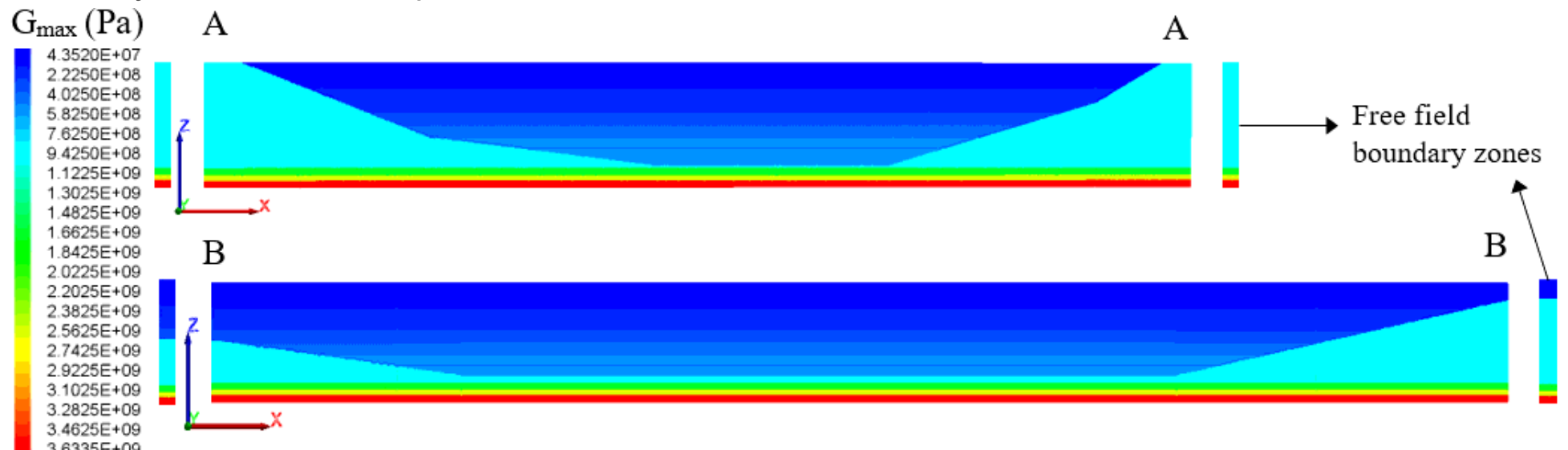

Figure 10

Finite Difference scheme of the numerical model of Gemlik basin in two directions 

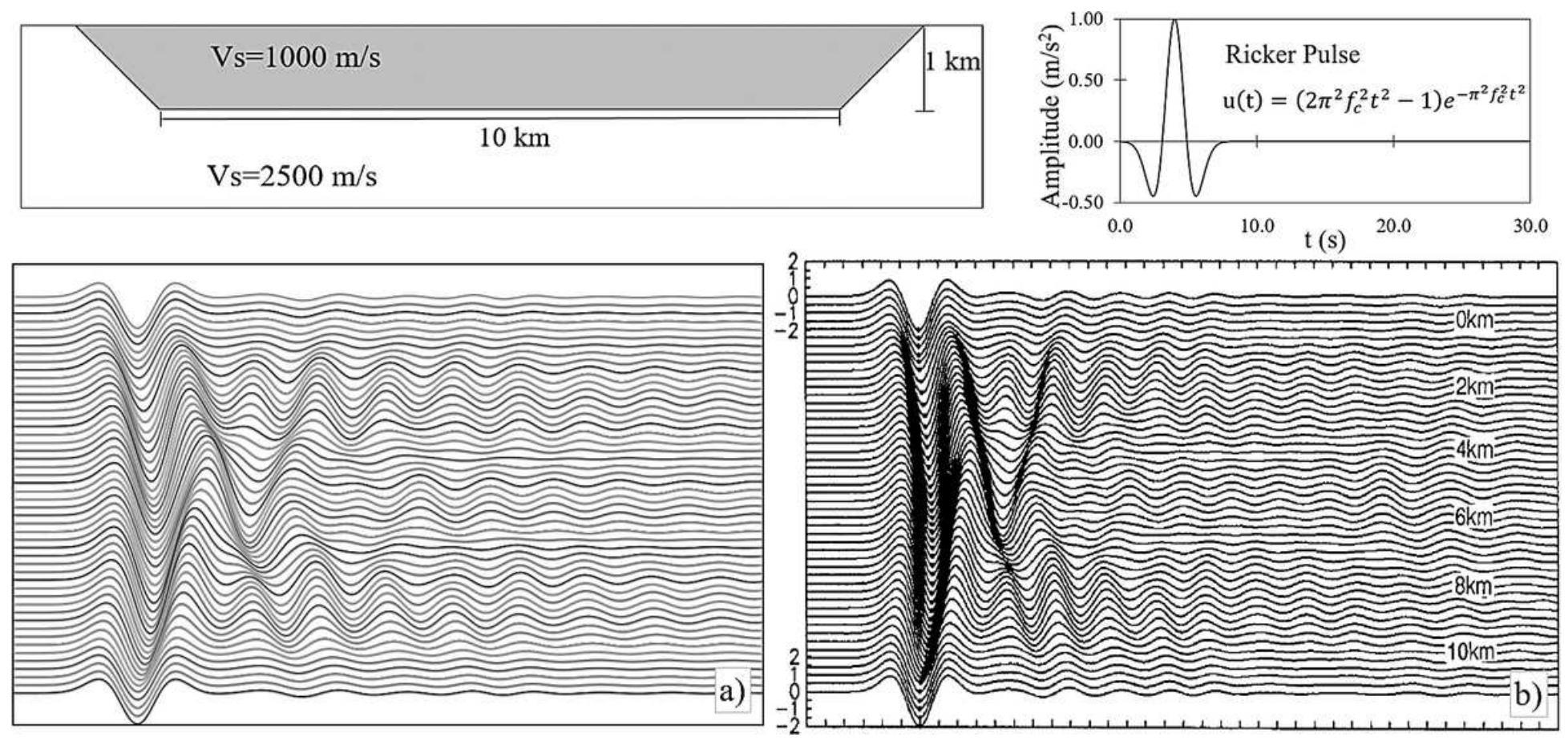

Figure 11

The specifications of the verification model and input motion (a) surface motion on the validation model in the study and (b) Kawase and Aki (1989)
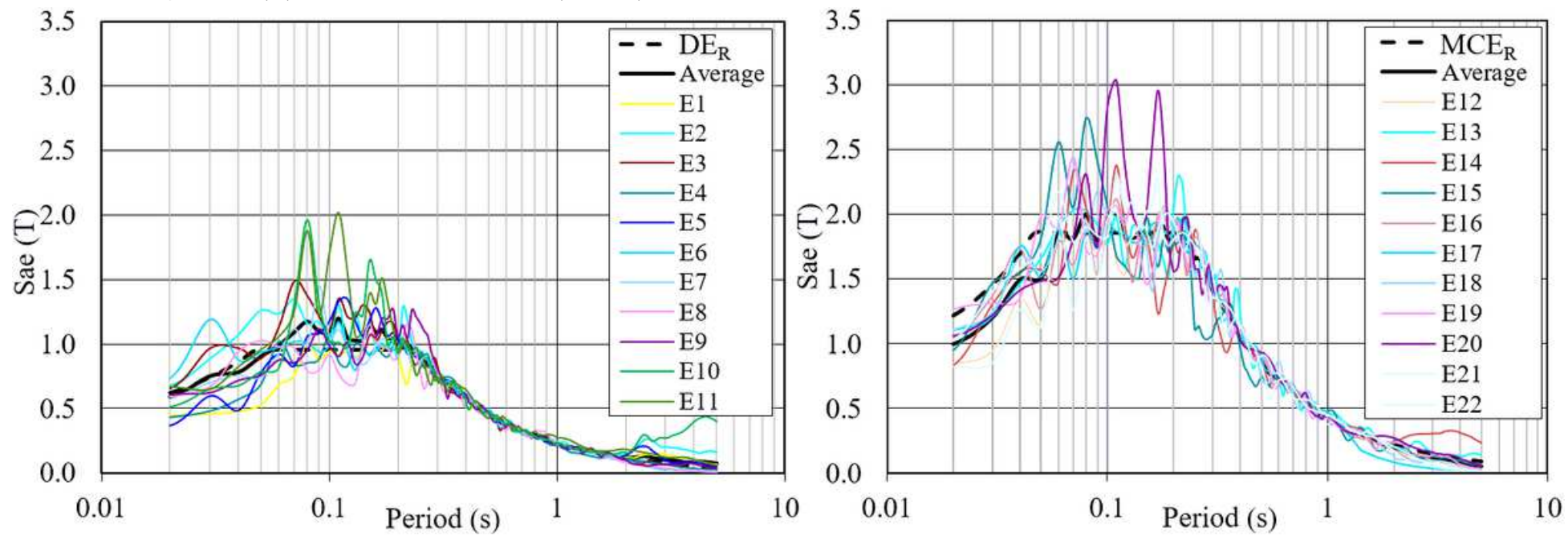

Figure 12

The selected earthquakes at seismic code-based target spectra of the site $(\xi=\% 5)$ 

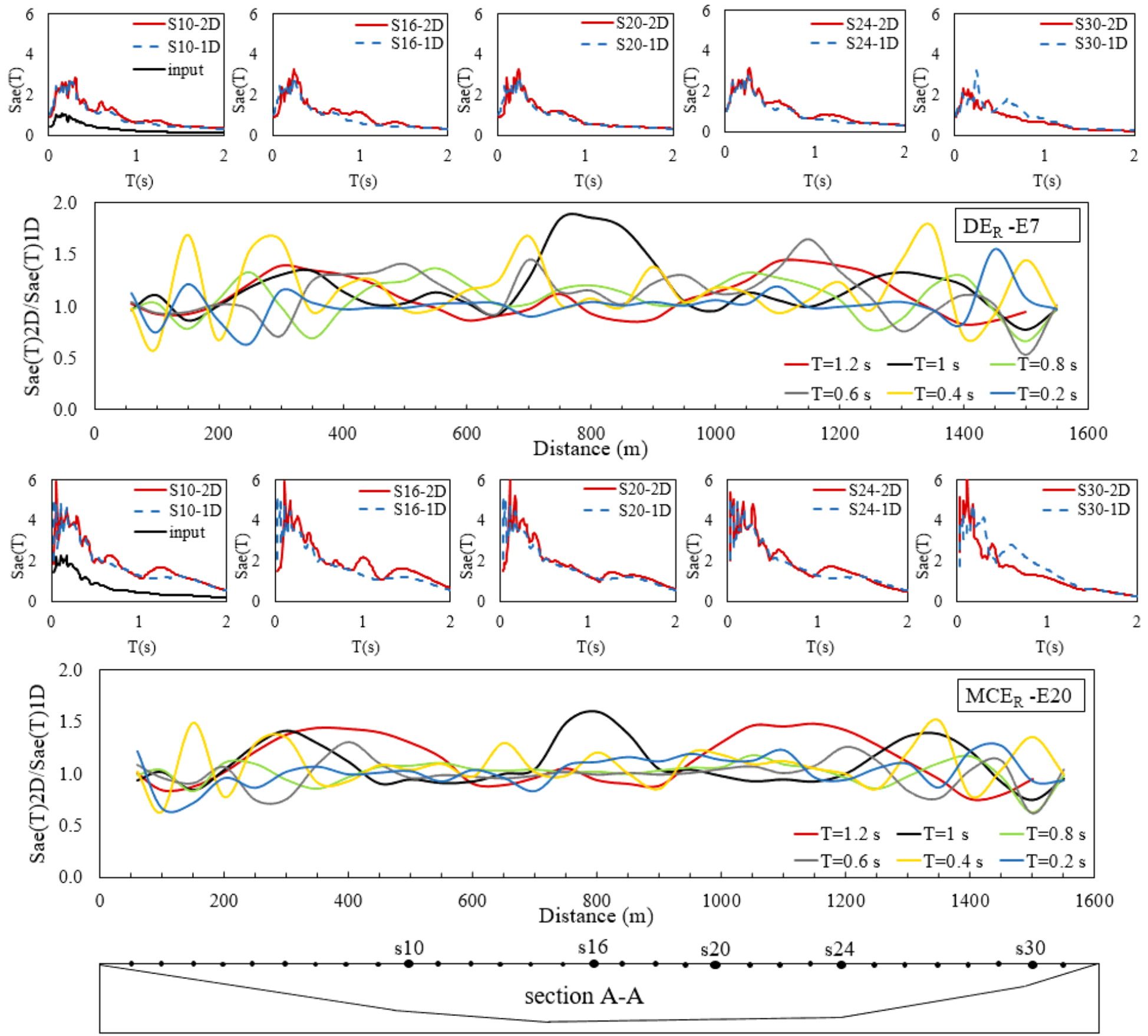

Figure 13

The variation of the response spectra and aggravation factors in $1 \mathrm{D}$ and $2 \mathrm{D}$ analyzes across the A-A section for levels of DER and MCER 

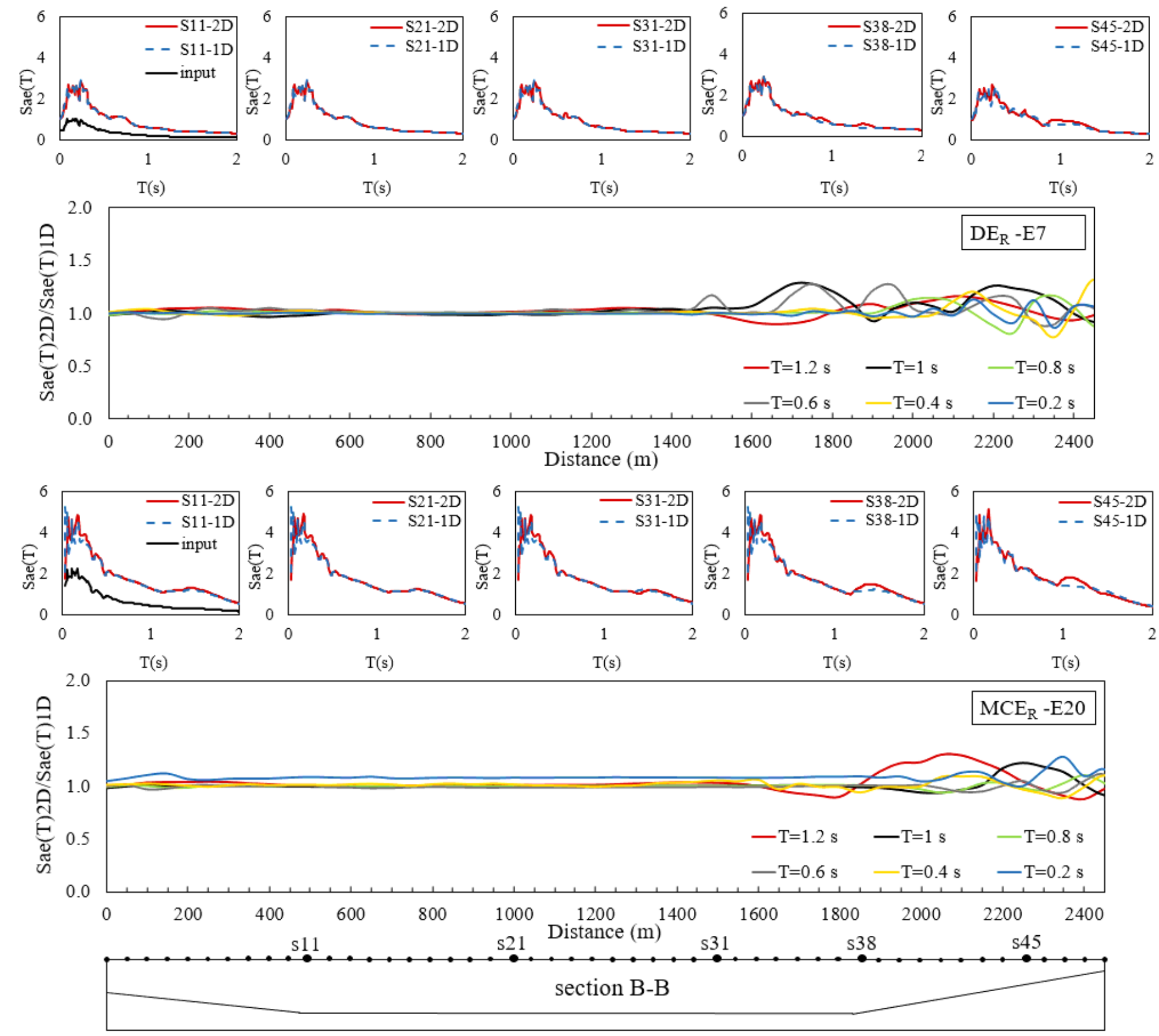

Figure 14

The variation of the response spectra and aggravation factors in 1D and 2D analyzes across the B-B section for levels of DER and MCER 


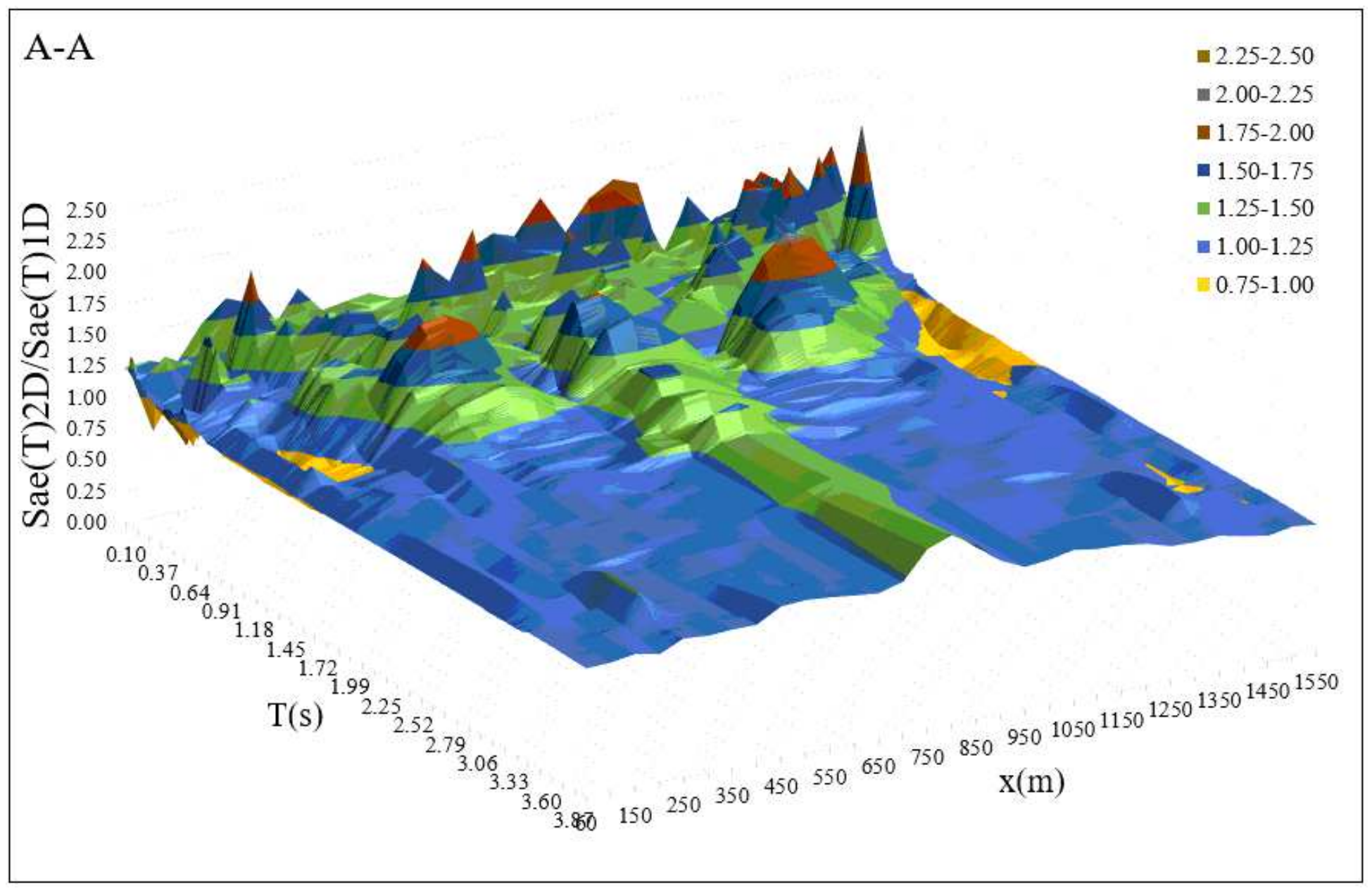

Figure 15

The maximum aggravation factors for MCER level in section A-A 


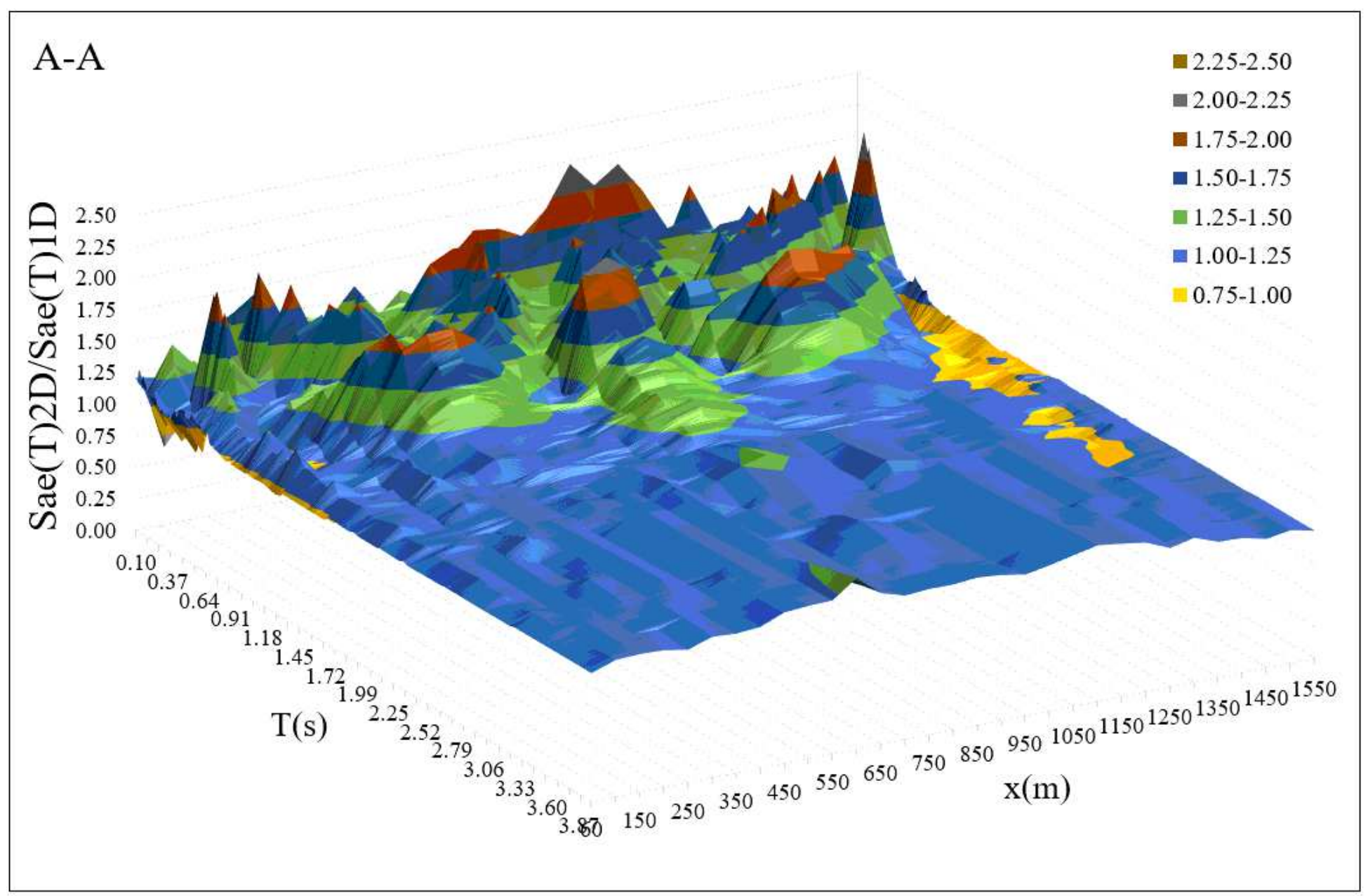

\section{Figure 16}

The maximum aggravation factors for DER level in section A-A 


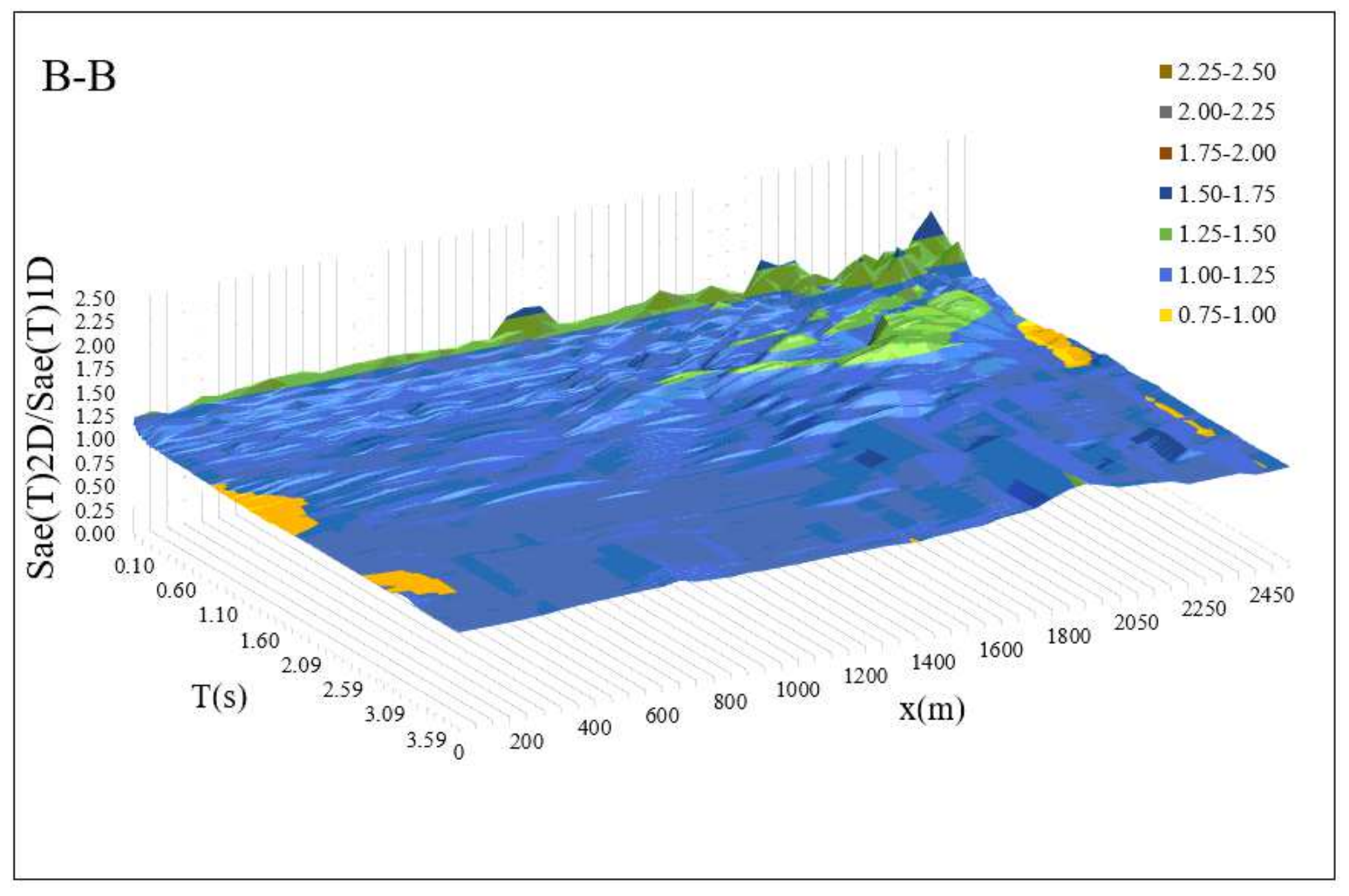

Figure 17

The maximum aggravation factors for MCER level in section B-B 


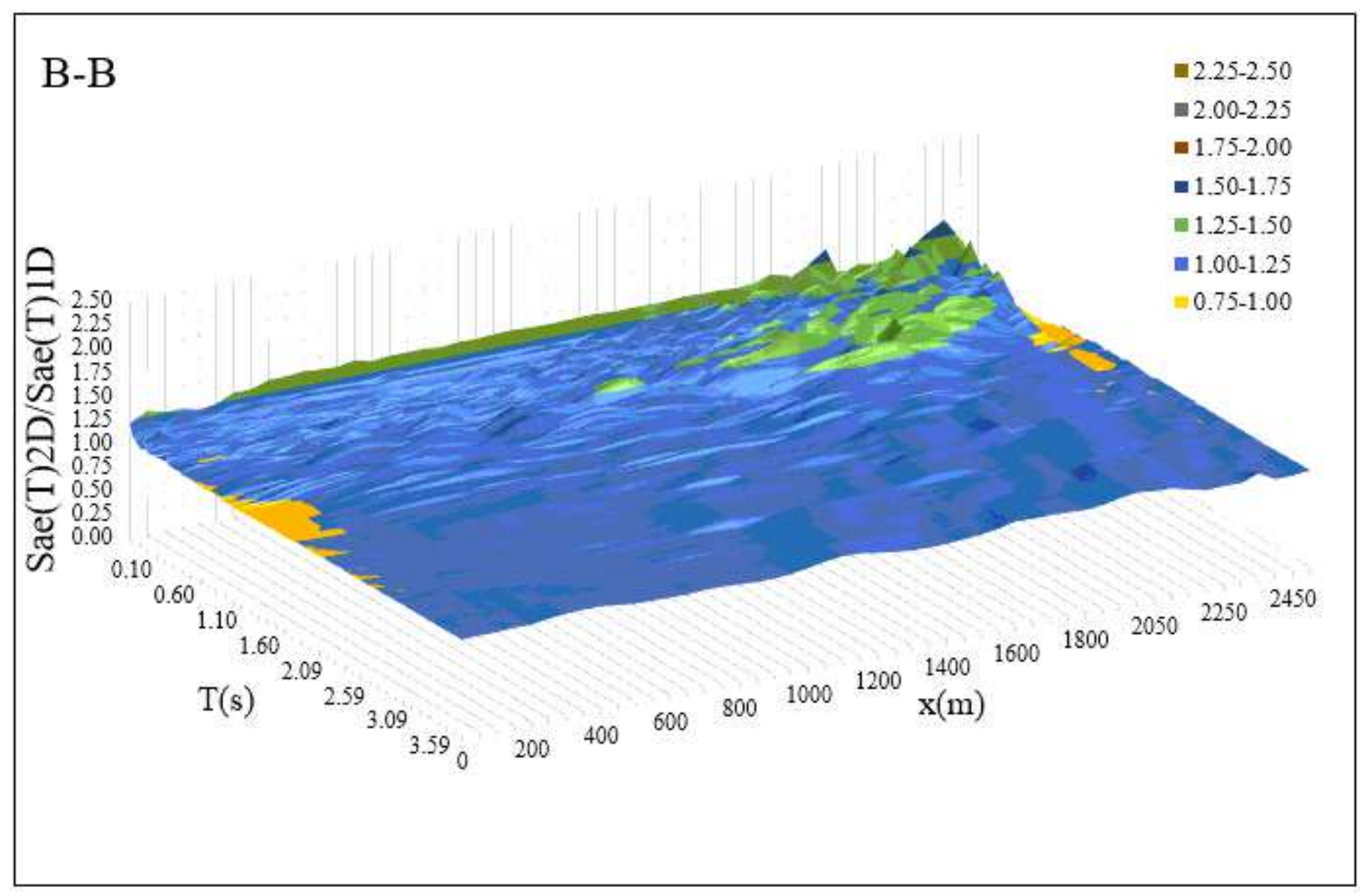

Figure 18

The maximum aggravation factors for DER level in section B-B 


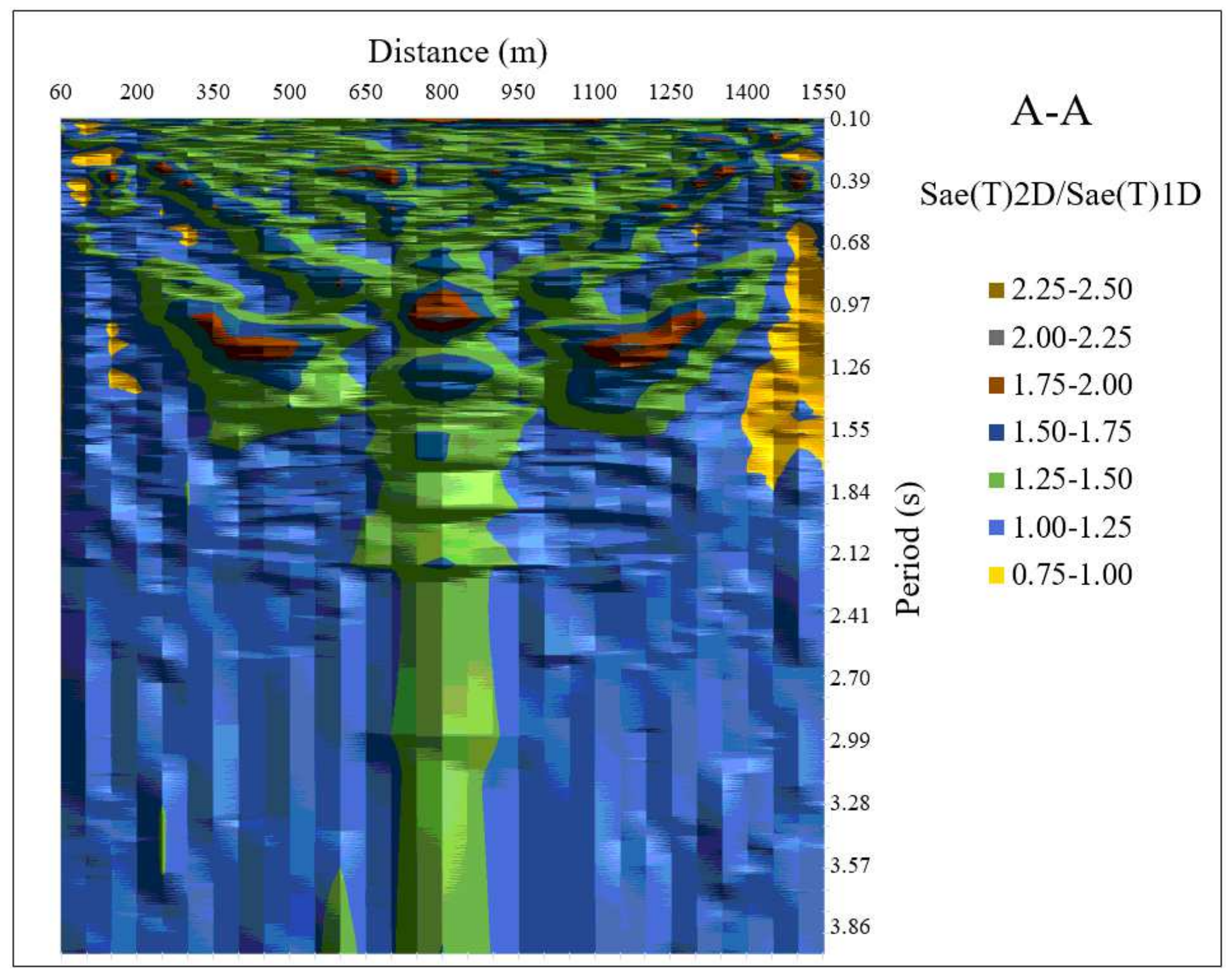

Figure 19

Maximum spectral aggravation factors for north-south direction in Gemlik basin 


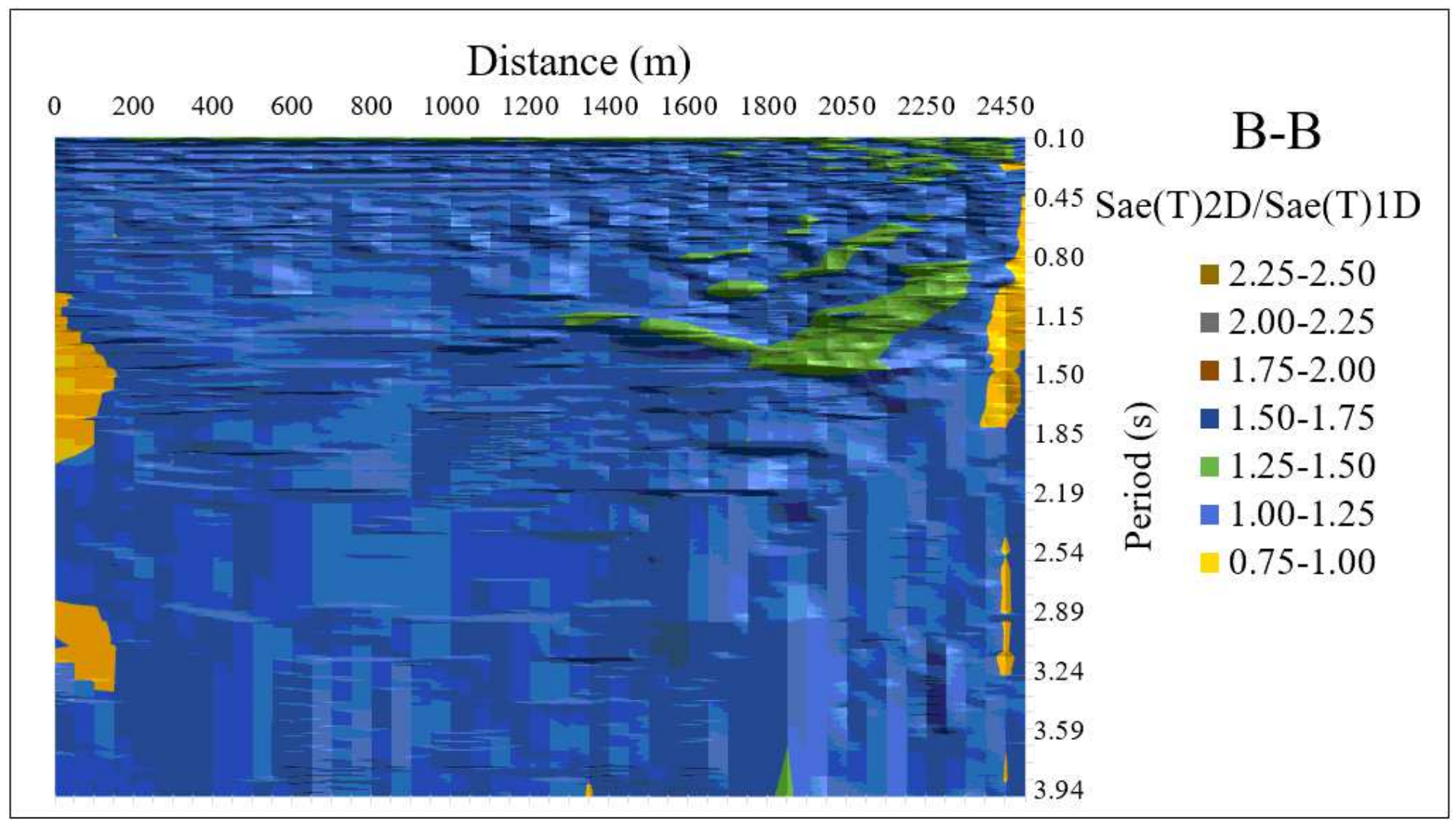

Figure 20

Maximum spectral aggravation factors for east-west direction in Gemlik basin 